\title{
A molecular dynamics simulation of hydrogen atoms collisions on an H-preadsorbed silica
}

\author{
surface
}

\author{
M. Rutigliano $a^{a}$, P. Gamallo ${ }^{b}$, R. Sayós ${ }^{b}$, S. Orlandini ${ }^{a}$, and M. Cacciatore $^{a}$
}

${ }^{a}$ CNR-IMIP (Institute of Inorganic Methodologies and Plasmas),

Via Amendola 122/D, 70126 Bari, (Italy)

b Departament de Química Física and Institut de Química Teòrica i Computacional (IQTC-UB), Univ. Barcelona, C. Martí i Franquès 1, 08028 Barcelona (Spain)

*Corresponding author: maria.rutigliano@,cnr.it 


\begin{abstract}
The interaction of hydrogen atoms and molecules with a silica surface is relevant for many research and technological areas. Here, the dynamics of hydrogen atoms colliding with an H-preadsorbed $\beta$-cristobalite (001) surface has been studied using a semiclassical collisional method in conjunction with a recently developed analytical potential energy surface based on Density Functional Theory (DFT) calculations. The atomic recombination probability via an Eley-Rideal (E-R) mechanism as well as the probabilities for other competitive molecular surface processes have been determined in a broad range of collision energies (0.04-3.0) eV eV) for off-normal $\left(\theta_{\mathrm{v}}=45^{\circ}\right)$ and normal $\left(\theta_{\mathrm{v}}=0^{\circ}\right)$ incidence and for two different surface temperatures $\left(\mathrm{T}_{\mathrm{S}}=300\right.$ and $1000 \mathrm{~K}) . \mathrm{H}_{2 \text {,gas }}$ molecules form in roto-vibrational excited levels while the energy transferred to the solid surface is below of $10 \%$ for all simulated conditions. Finally, the global atomic recombination coefficient $\left(\gamma_{\mathrm{E}-\mathrm{R}}\right)$ and vibrational state resolved recombination coefficients $\gamma(\mathrm{v})$ were calculated and compared with the available experimental values. The calculated collisional data are of interest in chemical kinetics studies and fluid dynamics simulations of silica surface processes in H-based low-temperature, low-pressure plasmas.
\end{abstract}

Keywords: Molecular surface processes, $\mathrm{H}+\mathrm{H}$-preadsorbed silica, Eley-Rideal reaction dynamics, plasma-surface interactions. 


\section{Introduction}

The interaction of plasmas with surfaces can lead to different surface processes active in different collisional energy regimes according to the behaviour of the gas-phase species and substrate involved. In particular, atom recombination at surfaces can be an effective source of rotovibrationally excited molecules and, at the same time, an effective process for surface atom abstraction and atom removal from the plasma region [1]. Such processes have a strong impact on the chemistry of the bulk region and at the plasma-surface interface. It is, in fact, well-established that the reactivity of molecular plasmas under low-pressure, low-temperature conditions depends on, and is often controlled by, the formation of energetically vibrationally activated molecules [25]. Therefore, it is important to understand the processes by which one can store vibrational quanta in the vibrational manifold of the active molecules in the plasma or gaseous media. There are many such processes and they are quite often difficult to describe and identify both from a theoretical and experimental point of view, although the identification and description of these processes at a molecular dynamical level has long been the objective of many research groups active in the wide area of plasma-chemistry and plasma-physics [6-8].

In-This paper we is focused on the molecular surface processes due to the interaction of a flux of $\mathrm{H}$ atoms colliding with a silica surface at low collisional energies.

Hydrogen plasmas are nowadays of great interest in different research areas of fundamental and technological interest such as micro-electronics, modern solar-cells, fusion reactors, astrophysics and aerothermodynamics. Fluxes of hydrogen atoms on silicon or silicon dioxide surfaces are used in the deposition of thin solid films, material grow and etching under low pressure plasma conditions where physical and structural properties must be well defined [9]. Hydrogen atom 
interaction with interstellar solid grains (graphite or silicate based surfaces) is of interest in astrophysics for the study of the chemistry on the early universe, and, in particular, to explain the great abundance of molecular hydrogen observed in the interstellar media [10]. Hydrogen is also the main constituent of Jovian atmosphere so that, in view of a possible future Jovian exploration, one of the major technological challenges is to plan a safe entry of spacecraft into Jovian's atmosphere by protecting the walls of the spacecraft from the heat fluxes produced by the heterogeneous recombination reactions of $\mathrm{H}$ atoms.

A similar problem, but for space shuttles re-entering into Earth's atmosphere, has been the subject of a large number of studies, experimental and theoretical, focused on the recombination reactions of $\mathrm{O}$ atoms on $\beta$-cristobalite surfaces [11-19].

There are not much theoretical calculations and experimental determinations for $\mathrm{H}$ atom recombination on silicon and silicon dioxide substrates, so that basic collisional data related to this heterogeneous process, such as the recombination probability, the related global recombination coefficient, the roto-vibrational distribution of the $\mathrm{H}_{2}$ molecules formed at the surfaces, are almost unknown. On the other hand, these and other collisional data are of fundamental importance also for kinetic modeling and computer fluid dynamics (CFD) simulations of the plasma-chemistry going on at the plasma-surface interface. The important effect of recombination coefficient $(\gamma)$ and of vibrational state resolved recombination $\gamma(\mathrm{v})$ coefficients on the heat flux has been already shown in several simulations [20-26]. The lack of collisional data for the system under study and in general for heterogeneous reactions in plasmas is mainly due to the highly specificity of the wall processes. In fact, reaction probabilities depend on properties of incident flux (kinetic energy, approaching geometry, etc.) and on the surface properties (temperature, morphology, coverage, etc.). However, some cautions should must be taken in the comparison of collisional data obtained 
via Molecular Dynamics (MD) and those determined in the experiments for the fact that under plasma conditions different processes can act simultaneously and influence each other. [1]

This work is devoted to MD simulation of hydrogen molecules formation by $\mathrm{H}$ atom recombination with an $\mathrm{H}$ atom preadsorbed on a silica ( $\beta$-cristobalite) surface assuming the EleyRideal (E-R) recombination reaction mechanism. The silica polymorph used is $\beta$-cristobalite, since it is the most stable silica crystalline polymorph at high temperature up to the melting point (i.e., $1983 \mathrm{~K})$.

The E-R recombination mechanism is a two steps step process. First, an $\mathrm{H}$ atom is adsorbed on the silica surface in a specific active surface site:

$$
\mathrm{H}_{\mathrm{gas}}+\text { silica } \rightarrow \mathrm{H}_{\mathrm{ad}} \text { silica }+\Delta \mathrm{E}_{(1)}
$$

then a hydrogen atom approaching the surface from the gas-phase reacts with the preadsorbed atom in a single or multiple collisions:

$$
\mathrm{H}_{\text {gas }}+\mathrm{H}_{\mathrm{ad}} * \text { silica } \rightarrow \mathrm{H}_{2}\left(\mathrm{X}^{1} \sum_{\mathrm{g}}{ }^{+} \mid \mathrm{v}, \mathrm{j}\right)+\text { silica }+\Delta \mathrm{E}_{(2)}
$$

thus forming an hydrogen molecule in a specific roto-vibrational state. $\Delta \mathrm{E}_{(\mathrm{i})}$ is the exothermicity of the process (i).

In our study, the rate-determining step (2) is assumed in the molecular dynamics simulation. It is worth noting that for E-R reaction to occur the atomic adsorption process (i.e., Eq. (1)) is a mandatory condition and this fact should be taken also into account depending on the experimental setup for a good comparison between the theoretical and the experimental recombination coefficients.

Of special interest is the energetics of the recombination reaction (2). The energy released in this process can be shared among the internal degrees of freedom of the newly formed $\mathrm{H}_{2}$ molecules (i.e., electronic transitions, molecular rotations, vibrations and translations) and, possibly, 
electrons) and the degrees of freedom of the silica substrate (phonons and/or electrons). It is of great importance to know, on the one hand, the extent to which the desorbing $\mathrm{H}_{2}$ molecules can be formed in vibrationally and rotationally excited states and, on the other hand, the heat flux transferred to the silica surface. Indeed, this issue, i.e. energy sharing mechanism, is among the most complex and intriguing problems relevant to recombination reactions on surfaces.

Experimentally, the global recombination coefficient $\gamma$ for $\mathrm{H}$ reacting over fused quartz and Pyrex has been formerly determined within the interval 194 - 1250 K [14] showing a not very good Arrhenius behavior with a small activation energy $\left(E_{a}=0.42 \pm 0.06 \mathrm{eV}\right)$ that would correspond mainly to the E-R reaction $\left(\gamma_{\mathrm{E}-\mathrm{R}}\right)$. Recombination coefficient at room temperature for hydrogen atom in low temperature plasma on fused silica was also determined by a pulsed plasma excitation technique in Ref. [27].

In this study we focus the attention is centered mainly on the study of reaction (2) in order to obtain $\gamma_{\mathrm{E}-\mathrm{R}}$, nevertheless, all the elementary processes originated by the collisions were also analyzed and discussed. The energetics of $\left.\mathrm{H}_{2, \mathrm{gas}} \mathrm{V}, \mathrm{j}\right)$ molecules formed in reaction (2) is solved by determining the energy transferred in the internal degrees of freedom of the molecule. The rotovibrational distributions as well as the average vibrational quantum number are determined together with the vibrational state-to-state recombination coefficient $\gamma(\mathrm{v})$.

The reaction dynamics has been determined using a semiclassical dynamics method [28]. The procedure followed can be summarized in three main steps: 1) building-up of a 3D model of silica surface for which the phonon structure is determined by performing a normal mode analysis of the silica lattice atom vibrational motions; 2) analytical representation of the PES obtained from electronic structure DFT calculations; 3) application of the semiclassical method to describe the 
dynamics of hydrogen atoms (one in gas phase and the another one preadsorbed) interacting with the silica surface.

We shall give here only a few details of steps 1) and 2) because these two points have been extensively described in previous papers. The surface model used (step 1) was already considered in Ref. [16] while the details about the DFT calculations as well as the analytical PES construction were reported in Ref. [29]. Thus, the present study is mainly focused on a detailed account and discussion of the main dynamical results (step 3).

The paper has the following structure: in Section 2 some minor details about the recently published analytical PES for the interaction of $\mathrm{H}_{\mathrm{gas}}$ and $\mathrm{H}_{2 \text {,gas }}$ with a $\beta$-cristobalite surface are reported; in Section 3 a brief overview of the dynamics method used is also given; in Section 4 molecular dynamics calculations are described whereas in Section 5 the principal results obtained for E-R reaction together with other competitive processes for off-normal and normal incidence and at different surface temperatures (i.e., $\mathrm{T}_{\mathrm{S}}=1000$ and $300 \mathrm{~K}$ ) are presented.

The last section is devoted to the summary of the main results obtained.

\section{3D Solid Surface Model and Analytical PES}

The recently published analytical PES [29] is based on periodic DFT-GGA calculations performed by means of the Vienna ab initio simulation package (VASP) [30-34]. An (1×1) unit cell was used for the adsorption studies along with a slab model formed by 6 layers of $\mathrm{SiO}_{2}$ with an outermost silicon layer. An additional hydrogen back layer was added for saturating the dangling bonds of terminal oxygen atoms. Details about the calculations can be found in Ref. [29]. The calculations were based on the generalized gradient correction (GGA) functional PerdewBurke-Ernzerhof (PBE) [35]. The previous DFT study [29] reports adsorption energies for several 
adsorption sites (i.e., T1, T1', B1, S2, B2, H1 drawn in Figure 1, obtaining that the most stable adsorption occurs on T1' site $\left(\mathrm{E}_{\mathrm{ad}}=2.10 \mathrm{eV}\right)$, where $\mathrm{H}-\mathrm{Si}$ bond is tilted in some extent with respect to the on top $\mathrm{T} 1$ site $\left(\alpha=55.5^{\circ}, \phi=45.0^{\circ}\right)$ [29], being $\mathrm{d}\left(\mathrm{H}_{\mathrm{ad}}-\mathrm{Si}\right)=1.51 \AA$. The adsorption on the other sites is less favorable $\left(\mathrm{E}_{\mathrm{ad}}=1.08,0.50,0.28,0.01\right.$ and $0.009 \mathrm{eV}$ for T1, S2, B1, H1 and B2 sites, respectively).

The analytical PES [29] was made up of sums of pairwise atom-atom interactions between each of the gas phase hydrogen atoms $\left(\mathrm{H}_{\mathrm{gas}(1)}\right.$ and $\mathrm{H}_{\mathrm{gas}(2)}$, hereafter $\mathrm{H}_{(1)}$ and $\left.\mathrm{H}_{(2)}\right)$ and each of the Si and $\mathrm{O}$ atoms that form the $\beta$-cristobalite $3 \mathrm{D}$ model. The $\beta$-cristobalite $(2 \times 2) 3 \mathrm{D}$ slab model consisted of 149 atoms distributed in ten layers according to the atom placement in the crystallographic $F d 3 m$ unit cell (nine of these layers are shown in Figure 1).

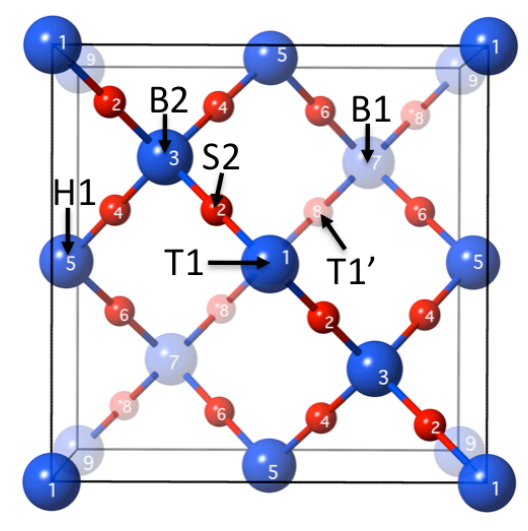

Figure 1. $\beta$-cristobalite (001) $F d 3 m$ top view with available sites (blue and red spheres stand for $\mathrm{Si}$ and $\mathrm{O}$ atoms, respectively). The label on each atom indicates the number of layer to which the atom belongs. The atoms in depth are rendered translucent in order to view clearer the outermost layers. The arrows indicate the location of the adsorption sites.

The phonon dynamics of the surface atoms was then developed by numerical diagonalization of the 3D-dynamical matrix of the force constants obtained assuming the Born-Mayer-Huggins as interaction potential of the $\mathrm{Si}$ and $\mathrm{O}$ lattice atoms [36]. The phonons eigenvalues and eigenvectors 
that enter into the scattering equations of motion are then obtained while the calculated phonon frequency spectrum [16] is compared with available literature data [37], leading to a good agreement.

The complete expression used for describing the $6 \mathrm{D}$ potential $\mathrm{V}\left(\mathrm{x}_{\mathrm{H}_{(1)}}, \mathrm{y}_{\mathrm{H}_{(1)}}, \mathrm{Z}_{\mathrm{H}_{(1)}}, \mathrm{x}_{\mathrm{H}_{(2)}}, \mathrm{y}_{\mathrm{H}_{(2)}}, \mathrm{Z}_{\mathrm{H}_{(2)}}\right)$ of the two atoms (i.e., 1,2$)$ interacting with a rigid $\beta$-cristobalite surface was defined as:

$$
\begin{aligned}
\mathrm{V}\left(\mathrm{x}_{\mathrm{H}_{(1)}}, \mathrm{y}_{\mathrm{H}_{(1)}}, \mathrm{Z}_{\mathrm{H}_{(1)}}, \mathrm{x}_{\mathrm{H}_{(2)}}, \mathrm{y}_{\mathrm{H}_{(2)}}, \mathrm{Z}_{\mathrm{H}_{(2)}}\right)= & \mathrm{V}_{\mathrm{H}_{2, g a s}}^{1 \mathrm{D}}(\mathrm{r})+\sum_{\mathrm{i}=1,2} \mathrm{~V}^{3 \mathrm{D}}\left(\mathrm{x}_{\mathrm{H}_{(\mathrm{i})}}, \mathrm{y}_{\mathrm{H}_{(\mathrm{i})}}, \mathrm{Z}_{\mathrm{H}_{(\mathrm{i})}}\right)+ \\
& +\mathrm{V}^{6 \mathrm{D}}\left(\mathrm{x}_{\mathrm{H}_{(1)}}, \mathrm{y}_{\mathrm{H}_{(1)}}, \mathrm{Z}_{\mathrm{H}_{(1)}}, \mathrm{X}_{\mathrm{H}_{(2)}}, \mathrm{y}_{\mathrm{H}_{(2)}}, \mathrm{Z}_{\mathrm{H}_{(2)}}\right)
\end{aligned}
$$

This equation is formed by the atom-surface terms $\left(\mathrm{V}^{3 \mathrm{D}}\right)$, one for each hydrogen atom, the $\mathrm{H}-\mathrm{H}$ gas phase interaction term $\left(\mathrm{V}^{1 \mathrm{D}}\right)$ and the term that accounts for the two hydrogen atoms interacting with the surface $\left(\mathrm{V}^{6 \mathrm{D}}\right)$. The $\mathrm{V}^{3 \mathrm{D}}$ term is split in two gas-solid pair-wise atomic interactions (i.e., $\mathrm{H}$ $\mathrm{Si}$ and $\mathrm{H}-\mathrm{O})$ :

$$
\mathrm{V}^{3 \mathrm{D}}\left(\mathrm{x}_{\mathrm{H}_{(\mathrm{i})}}, \mathrm{y}_{\mathrm{H}_{(\mathrm{i})}}, \mathrm{z}_{\mathrm{H}_{(\mathrm{i})}}\right)=\left[\sum_{\mathrm{j}=1}^{\mathrm{N}_{\mathrm{Si}}=54} \mathrm{~V}_{\mathrm{H}_{(\mathrm{i})}-\mathrm{Si}_{(\mathrm{j})}}\left(\mathrm{R}_{\mathrm{ij}}\right)\right]+\left[\sum_{\mathrm{j}=55}^{\mathrm{N}_{\mathrm{o}}=149} \mathrm{~V}_{\mathrm{H}_{(\mathrm{i})}-\mathrm{O}_{(\mathrm{j})}}\left(\mathrm{R}_{\mathrm{ij}}\right)\right]
$$

where $\mathrm{V}\left(\mathrm{x}_{\mathrm{H}_{(\mathrm{i})}}, \mathrm{y}_{\mathrm{H}_{(\mathrm{i})}}, \mathrm{z}_{\mathrm{H}_{(\mathrm{i})}}\right)$ corresponds to the $i$-th hydrogen atom Cartesian coordinates and $\mathrm{R}_{\mathrm{ij}}$ stands for the distances between the gas phase $i$-th hydrogen atom and the $j$-th $\mathrm{Si}$ or $\mathrm{O}$ atoms that belong to the 3D slab model. This term fitted a total of 160 DFT data points for $\mathrm{H}$ adsorption on the above-mentioned six selected high-symmetry sites (i.e., T1, T1', B1, S2, B2, H1 in Figure 1) by means of modified Morse-like functions not showed here for brevity purposes [29]. This kind of functions is appropriate since the adsorption over all these sites was not activated. During the fitting procedure, much more attention was paid to describing satisfactorily the energetics of 
minimum adsorption sites. The fitting reports the following adsorption energies: $2.06,0.75,0.14$, 0.16, 0.004 and $0.006 \mathrm{eV}$ for T1', T1, S2, B1, H1 and B2 sites. A good agreement with DFT data was achieved in the final fit, mainly for the most important site (T1'). The effect of trying to obtain the best fit for all the sites considered makes that the DFT adsorption curve for T1' site was matched by the fitting function in both depth and position of the minimum but not in the shape. Nevertheless, the global fit was good enough to reproduce the stability of T1' site (where the hydrogen adatom is preadsorbed during the dynamical treatment) whereas it reproduced qualitatively also the adsorption on the other possible sites around the surface.

The $\mathrm{V}^{1 \mathrm{D}}$ term corresponds to the fitting of DFT data for $\mathrm{H}_{2, \text { gas }}$ curve by means of a Morse-like potential, taking as zero of energies the asymptotic value $\left(2 \mathrm{H}_{\mathrm{gas}}\right.$ atoms in their lowest doublet states) corresponding to two $\mathrm{H}_{\mathrm{gas}}$ atoms in their lowest electronic state (i.e., ${ }^{2} \mathrm{~S}$ ),

$$
\mathrm{V}_{\mathrm{H}_{2, \text { gas }}}^{1 \mathrm{D}}(\mathrm{r})=\mathrm{D}_{\mathrm{H}_{2}} \cdot\left\{1-\exp \left[-\alpha\left(\mathrm{r}-\mathrm{r}^{\mathrm{eq}}\right)\right]\right\}^{2}-\mathrm{D}_{\mathrm{H}_{2}}
$$

where $r$ is the internuclear distance between the two hydrogen atoms. The final fitted parameters reported in Ref. [29] drive lead to dissociation energy and equilibrium internuclear distance values that compare quite well with the experimental ones [38].

For the $\mathrm{V}^{6 \mathrm{D}}$ term $2650 \mathrm{DFT}$ data points were fitted for different approaches of the second $\mathrm{H}_{(2)}$ atom keeping fixed the $\mathrm{H}_{(1)}$ adatom on $\mathrm{T} 1$ ' site, the most stable adsorption site. Thus, $\mathrm{V}^{6 \mathrm{D}}$ term was expressed as:

$$
\mathrm{V}^{6 \mathrm{D}}\left(\mathrm{x}_{\mathrm{H}_{(\mathrm{i})}}, \mathrm{y}_{\mathrm{H}_{(\mathrm{i})}}, \mathrm{z}_{\mathrm{H}_{(\mathrm{i})}}\right)=\left(1-\mathrm{f}_{1}\right) \cdot\left(1-\overline{\mathrm{f}}_{1}\right) \cdot\left(1-\overline{\overline{\mathrm{f}_{1}}}\right) \cdot\left[\sum_{\mathrm{i}=1,2}\left(\sum_{\mathrm{j}=1}^{\mathrm{N}_{\mathrm{si} / 0}=149} \mathrm{~V}_{\mathrm{H}_{(\mathrm{i})}-\mathrm{Si} / \mathrm{O}_{(\mathrm{j})}}\left(\mathrm{R}_{\mathrm{ij}}\right)\right)\right]
$$

where the analytical expressions for the $\mathrm{H}_{(\mathrm{i})}-\mathrm{Si} / \mathrm{O}_{(\mathrm{j})}$ interactions were also modified Morse-like functions and the switching functions (i.e., $\mathrm{f}_{\mathrm{i}}$ and $\overline{\mathrm{f}}_{\mathrm{i}}$ for $\mathrm{i}=1,2$ and $\overline{\overline{\mathrm{f}_{i}}}$ ) were are the responsible of delimiting the strong interaction area [18]. 
The energy values associated to atomic adsorption (Eq. (1)) and E-R (Eq. (2)) processes (i.e., $\Delta \mathrm{E}_{(1)}$ and $\Delta \mathrm{E}_{(2)}$, respectively) derived from the global PES (Eq. (3)) are $-2.4 \mathrm{eV}$ and $-2.1 \mathrm{eV}$, respectively. Figure $2 \mathrm{a}$ shows the reference frame used during the study of $\mathrm{H}$ interaction with a $\mathrm{H}-$ preadsorbed surface. The internal coordinates used are the internuclear $\mathrm{H}_{(1)}-\mathrm{H}_{(2)}$ distance (r), and the two angles $(\theta$ and $\phi)$ that define the orientation of the approaching. The angle that form internuclear distance and the negative $z$ axis corresponds to $\theta$ and the azimuthal angle $\phi$ corresponds to the angle formed by impact parameter, that is the orientation of projected internuclear distance onto the $x y$ plane, with respect $x$ axis.

The atomic incoming velocity angle $\left(\theta_{\mathrm{v}}\right)$ is defined with respect to the negative $z$ axis (e.g., $0^{\circ}$ for normal incidence and $45^{\circ}$ for off-normal incidence) and its projection onto the $x y$ plane (i.e., the azimuthal $\phi_{\mathrm{v}}$ angle) was uniformly sampled within the $0-360^{\circ}$ interval.

With respect to E-R channel and as discussed in our previous paper [29] focused on the construction of the analytical PES, the barrier for this reaction depends strongly on the direction of the incoming $\mathrm{H}_{(2)}$ atom. The DFT study for E-R reaction was made preadsorbing $\mathrm{H}_{(1)}$ atom over a T1' site. Thus, when $\mathrm{H}_{(2)}$ atom approaches, the preferred direction is forming a $\phi=55^{\circ}$ angle with the $x$ direction, along the $\mathrm{B} 1$ sites line (Fig. 2b). If the $\mathrm{H}_{(2)}$ atom comes in the opposite T1' site direction (i.e., the geminal T1' site located over the same $\mathrm{Si}$ atom) the formation of $\mathrm{H}_{2, \text { gas }}$ is not produced since the geminal adsorption is highly exothermic $\left(\mathrm{E}_{\mathrm{ad}}=3.02 \mathrm{eV}\right.$ per atom $)$ as reported in Table 2 of the already published contribution [29]. The resulting analytical surface (Eq. (3)) shows that the most favorable incoming angle corresponds to $\phi=55^{\circ}$ (Figure $2 \mathrm{~b}$ ) and for an impact parameter value of $0.5 \AA$ the barrier is very small (i.e., $0.02 \mathrm{eV}$ with respect reactants), but when the $\phi$ angle changes the barrier becomes higher. Thus, for $\phi=45^{\circ}$ in B1 direction, the barrier respect reactants increases until a value of $0.16 \mathrm{eV}$. These values are in agreement with DFT based results 
reported in Ref. [26] that predict a barrier height close to $0.08 \mathrm{eV}$ for the preferred an-approaching angle of $\phi=55^{\circ}$.

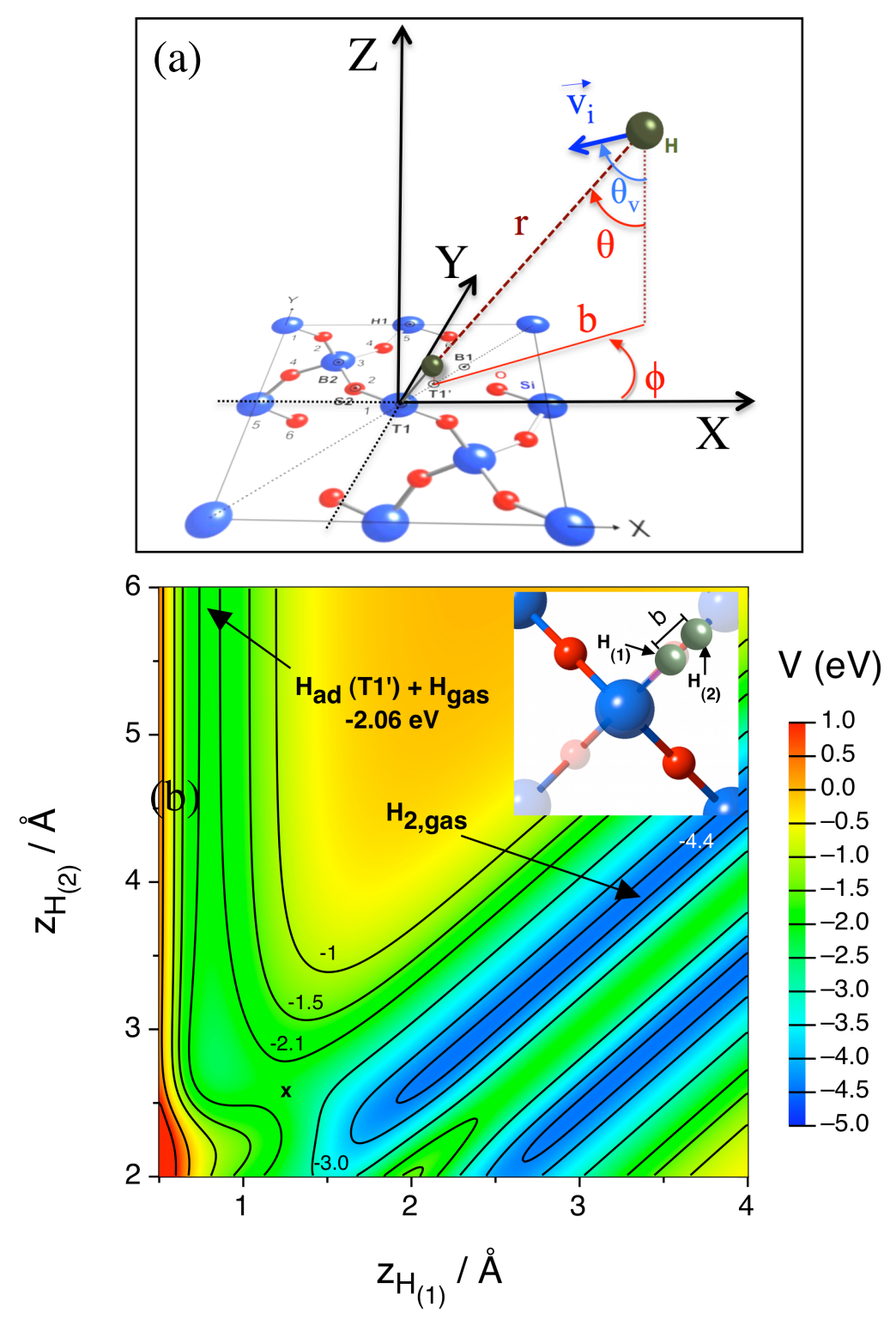

Figure 2 a) Coordinate system for $\mathrm{H}_{\text {gas }}$ atom interacting with a $\mathrm{H}$-preadsorbed silica surface. The internal coordinates $(r, \theta, \phi)$ define the molecular hydrogen orientation, while $\left(\theta_{v}, \phi_{v}\right)$ define the orientation angles for the incoming velocity vector $\left(\vec{v}_{\mathrm{i}}\right)$. (b) contour plot of the analytical PES for the $z$ variation of $\mathrm{H}_{(1)}$ and $\mathrm{H}_{(2)}$ maintaining $x$ and $y$ coordinates of both atoms fixed. The inset clarifies the location of both $\mathrm{H}$ atoms. $\mathrm{H}_{(1)}$ is located on $x, y$ coordinates corresponding to T1' site $\left(\phi=45^{\circ}\right)$ and $\mathrm{H}_{(2)}$ is on T1'-B1 line at a fixed impact parameter $(\mathrm{b}=0.5 \AA)$. The cross symbol stands for the transition state position. The zero of energy is taken as $\left[\mathrm{H}_{\text {gas }}+\mathrm{H}_{\text {gas }}+\right.$ surface $]$. 


\section{The Semiclassical Dynamics Method}

The method assumed to describe the reaction dynamics of the two hydrogen atoms interacting with the $\beta$-cristobalite surface is the semiclassical method described in great detail in the $\mathrm{G}$. Billing's book [28]. The method has been used to describe the dynamics of various atom recombination and dissociative chemisorption processes catalyzed by surfaces (see for example Ref. [17]) and takes into account several chemical-physics effects which are typical of the heterogeneous character of the system under study, among which: e.g., the crystallographic structure of the silica surface, the silica phonon structure and dynamics, and the interaction between the silica phonons and the $\mathrm{H}$ atoms hitting the surface.

According to the semiclassical approach [28], the dynamics of the both gas phase and adsorbed hydrogen atoms is described classically, whereas the lattice atom vibrations are quantized.

The equations of motion of the two hydrogen atoms are solved using an effective potential defined by:

$$
\mathrm{V}_{\text {eff }}\left(\mathrm{t}, \mathrm{T}_{\mathrm{S}}\right)=\left\langle\Psi_{\mathrm{ph}}\left(\mathrm{t}, \mathrm{T}_{\mathrm{S}}\right)\left|\mathrm{V}_{\text {int }}(\mathbf{R})\right| \Psi_{\mathrm{ph}}\left(\mathrm{t}, \mathrm{T}_{\mathrm{S}}\right)\right\rangle
$$

where $\mathbf{R}$ is the two-body distance vector between the interacting $\mathrm{H}$ atoms and the lattice atoms. $\mathrm{V}_{\text {int }}(\mathbf{R})$ is given by Eq. (3) and $\Psi_{\mathrm{ph}}$ is the wave function for the quantum phonons.

Thus, the motion of the atoms and molecules in the gas phase or at the surface is obtained by numerical solution of the Hamilton's equations of motion using the effective Hamiltonian $\mathrm{H}_{\mathrm{eff}}\left(\mathrm{t}, \mathrm{T}_{\mathrm{s}}\right)$ given by,

$$
\mathrm{H}_{\text {eff }}\left(\mathrm{t}, \mathrm{T}_{\mathrm{s}}\right)=\sum_{\mathrm{i}=1}^{2} \frac{\mathrm{P}_{\mathrm{i}}^{2}}{2 \mathrm{~m}_{\mathrm{i}}}+\mathrm{V}_{\mathrm{eff}}\left(\mathrm{t}, \mathrm{T}_{\mathrm{s}}\right)+\Delta \mathrm{E}_{\mathrm{ph}}\left(\mathrm{t}, \mathrm{T}_{\mathrm{s}}\right)
$$


where the first term is the kinetic energy of the gas phase atoms and the last term is the energy exchanged between the hydrogen atoms and the silica substrate [28].

This method is expected to be valid within the limits imposed by a classical treatment of the translational and roto-vibrational motion of the gas phase particles interacting with the surface. Those limits are mainly related to quantum tunneling effects and to the non-conservation of the zero-point energy. Because of the large energy delivered in the recombination process and with such an insignificant barrier, the semiclassical approach is expected to be in substantial agreement with quantum results as well as quasiclassical ones. This fact has been confirmed previously, in the study of the isotope effect on $\mathrm{H}$ recombination on a rigid $\mathrm{Cu}(111)$ surface and also on graphite [39-41].

The potential energy surface for $\mathrm{H}_{2}$ formation through $\mathrm{H}$ recombination on silica displays a very low energetic barrier to reaction (see previous section). and This point makes a classical dynamics treatment feasible even for the lightest nuclei in a wide collisional regime (from sub-thermal energies up to several eV).

\section{Molecular Dynamic Calculations}

Reaction (2) has been simulated by considering collisions of $\mathrm{H}_{\mathrm{gas}}$ with an $\mathrm{H}$-preadsorbed $\beta$ cristobalite surface. The adatom is located on the T1' site at a variable distance around the chemisorption equilibrium one and it is assumed in thermal equilibrium with the silica surface so that the normal component of initial momentum is set equal to $K_{B} \cdot T_{S}$, (where $K_{B}$ is the Boltzmann constant). The azimuthal angle $(\phi)$ has been sampled by selecting randomly the initial $(x, y)$ position coordinates of the incoming $\mathrm{H}_{\text {gas }}$ atom are chosen randomly within the $(1 \times 1)$ unit cell, while its collision energy $\left(\mathrm{E}_{\mathrm{kin}}\right)$ is varied in the range $(0.04-3.0) \mathrm{eV}$. The effect of the incidence 
angle of the atomic flux hitting the surface and of the surface temperature on the reaction dynamics has been also explored. Then to investigate the incidence angle effect two sets of initial conditions are assumed for $\mathrm{H}_{\text {gas: }}$ : in one case the gas phase $\mathrm{H}$ atom strikes the silica surface in an off-normal direction $\left(\theta_{\mathrm{v}}=45^{\circ}\right)$, while in the second simulation $\mathrm{H}_{\mathrm{gas}}$ approaches the surface in the normal direction $\left(\theta_{\mathrm{v}}=0^{\circ}\right)$ (being $\theta_{\mathrm{v}}$ the angle between the incoming atom velocity vector and the normal to the surface plane the negative $\mathrm{Z}$ axis, Figure 2a). To explore the surface temperature effect we took two surface temperatures have been selected, $T_{S}=1000 \mathrm{~K}$ and $300 \mathrm{~K}$. For each initial condition and collision energy at least 15000 trajectories have been propagated. For the complete set of values of $E_{\text {kin }}$ the number of trajectories run was enough to assure a convergence of the calculated collisional observables (i.e., probabilities of the various surface processes, vibrational distributions in the final molecular states, etc.). As stated above-mentioned in the Introduction the simulated conditions are only an approximation of those more complex that exist in plasma conditions. Just to mention a few differences: here we consider a perfect surface is considered while real surfaces can have defects and contaminations; besides, since the method is singlecollision, the initial coverage $\left(1.97 \times 10^{14}\right.$ atom $/ \mathrm{cm}^{2}$, corresponding to one adsorbed atom in the crystallographic unit cell) is preserved in the trajectory evolution, while surface coverage is continually evolving if a flux is supposed. Furthermore $\mathrm{H}_{\text {gas }}$ atom impinges the surface with a welldefined kinetic energy and direction, while in a real plasma kinetic energy as well as incidence directions are subject to change due to collisions and interaction with other plasma radicals. This last approximation is partially overcome by averaging the calculated probabilities on $\mathrm{E}_{\mathrm{kin}}$ assuming a flux of $\mathrm{H}$ atoms with kinetic energies distributed according to the Boltzmann equation for a given $\mathrm{T}_{\text {gas }}$ (see Eq.(10) later). 
The final state analysis of the trajectories shows that the following surface processes are energetically open to the collision dynamics:

$$
\mathrm{H}_{\mathrm{gas}}+\mathrm{H}_{\mathrm{ad}} * \text { silica } \rightarrow\left\{\begin{array}{cc}
\mathrm{H}_{2, \mathrm{gas}}(\mathrm{v}, \mathrm{j})+\text { silica } & \text { (a) } \\
\mathrm{H}_{\mathrm{gas}}+\mathrm{H}_{\mathrm{ad}} * \text { silica } & \text { (b) } \\
\mathrm{H}_{\mathrm{ad}} * \text { silica }+\mathrm{H}_{\mathrm{gas}} & \text { (c) } \\
\mathrm{H}_{\mathrm{ad}} * \text { silica }+\mathrm{H}_{\mathrm{ad}} * \text { silica } & \text { (d) } \\
\left(\mathrm{H}_{2}\right)_{\mathrm{ad}} * \text { silica } & \text { (e) } \\
\mathrm{H}_{\mathrm{gas}}+\mathrm{H}_{\mathrm{gas}}+\text { silica } & \text { (f) }
\end{array}\right.
$$

The classification of a trajectory is done according to both geometrical and/or energetical requirements. Thus, a $\mathrm{H}_{2, \text { gas }}$ molecule is considered as formed when the interatomic $\mathrm{H}-\mathrm{H}$ distance $\mathrm{r}$ is lesser than $2.5 \AA$ and the distance from the surface to the centre of mass of the molecule is larger than $7 \AA$. The rotational and vibrational states of hydrogen molecules, assuming the Morse oscillator given in Eq. (5), were are analyzed in terms of the action-angle variables using the semiclassical quantization rules [42].

A hydrogen atom is considered adsorbed on the surface when the available energy to escape from the chemisorption potential well $\left(\Delta \mathrm{E}_{\mathrm{esc}}\right)$ is lower than the effective potential $\left(\mathrm{V}_{\text {eff }}\right)$ defined in Eq. (7). In particular, the $\Delta \mathrm{E}_{\text {esc }}$ term is defined as $\mathrm{E}_{\text {tot }}-\Delta \mathrm{E}_{\mathrm{ph}}-\mathrm{E}_{0}$ where $\mathrm{E}_{\text {tot }}$ is the total energy for a specific collision event, necessarily conserved in the course of the trajectory, $\mathrm{E}_{0}$ is the zero point energy of the chemisorbed atom and $\Delta \mathrm{E}_{\mathrm{ph}}$ was already defined as the energy exchanged between both $\mathrm{H}$ atoms and the surface. Finally, the atoms are considered in gas phase when their distances from the surface are larger than $7 \AA$ and the direction of their velocity vectors points to the vacuum. According to these criteria, the probability associated to all the processes detailed in Eqs. (9 a-f) (i.e., E-R recombination, atomic reflection, atomic adsorption + desorption, atomic adsorption, 
molecular formation + adsorption, and atomic desorption, respectively) was is determined as a function of $\mathrm{E}_{\mathrm{kin}}$ of the incoming $\mathrm{H}_{\mathrm{gas}}$ atom. For the case of E-R reaction (Eq. (9a)) the energetic of the new formed $\mathrm{H}_{2 \text {,gas }}$ molecules was is also resolved by determining the average energy fraction transferred to their translational, vibrational and rotational degrees of freedom as well as the average energy fraction interchanged with the surface. The global recombination coefficient $\gamma_{\mathrm{E}-\mathrm{R}}$ $\left(\mathrm{T}_{\mathrm{S}}, \mathrm{T}_{\mathrm{gas}}\right)$ is obtained from the atomic recombination probabilities [17]:

$$
\gamma_{\mathrm{E}-\mathrm{R}}\left(\mathrm{T}_{\text {gas }}, \mathrm{T}_{\mathrm{S}}\right)=\frac{2}{\left(\mathrm{~K}_{\mathrm{B}} \mathrm{T}_{\text {gas }}\right)^{3 / 2} \sqrt{\pi}} \int_{0}^{\infty} \mathrm{P}_{\mathrm{E}-\mathrm{R}}\left(\mathrm{E}_{\mathrm{kin}}, \mathrm{T}_{\mathrm{S}}\right) \sqrt{\mathrm{E}_{\text {kin }}} \cdot \mathrm{e}^{\frac{-\mathrm{E}_{\mathrm{B}} \mathrm{K}_{\mathrm{gas}}}{\mathrm{T}_{\text {gas }}}} \mathrm{dE_{ \text {kin } }}
$$

where $\mathrm{T}_{\text {gas }}$ is the gas temperature and $\mathrm{E}_{\mathrm{kin}}$ is the collision energy of the $\mathrm{H}_{\text {gas }}$ atom impinging the $\mathrm{H}$ preadsorbed one on the $\beta$-cristobalite surface. Likewise the state-to-state recombination coefficients $\gamma(\mathrm{v})(\mathrm{v}=1-12)$, can be obtained by replacing $\mathrm{P}_{\mathrm{E}-\mathrm{R}}\left(\mathrm{E}_{\mathrm{kin}}, \mathrm{T}_{\mathrm{S}}\right)$ with $\mathrm{P}_{\mathrm{E}-\mathrm{R}}\left(\mathrm{v}, \mathrm{E}_{\mathrm{kin}}, \mathrm{T}_{\mathrm{S}}\right)$, that is the probability that for a given $\mathrm{E}_{\mathrm{kin}}$ and $\mathrm{T}_{\mathrm{S}}$, atoms recombine to form a molecule in the vibrational quantum number $\mathrm{v}$, whatever its rotational state.

\section{Results and Discussion}

In Figure 3 probabilities for the complete set of elementary surface processes, described in Eqs. (9a-f), for both off-normal and normal incidence of $\mathrm{H}_{\mathrm{gas}}$ and $\mathrm{T}_{\mathrm{S}}=1000 \mathrm{~K}$ are reported as a function of collision energy. 

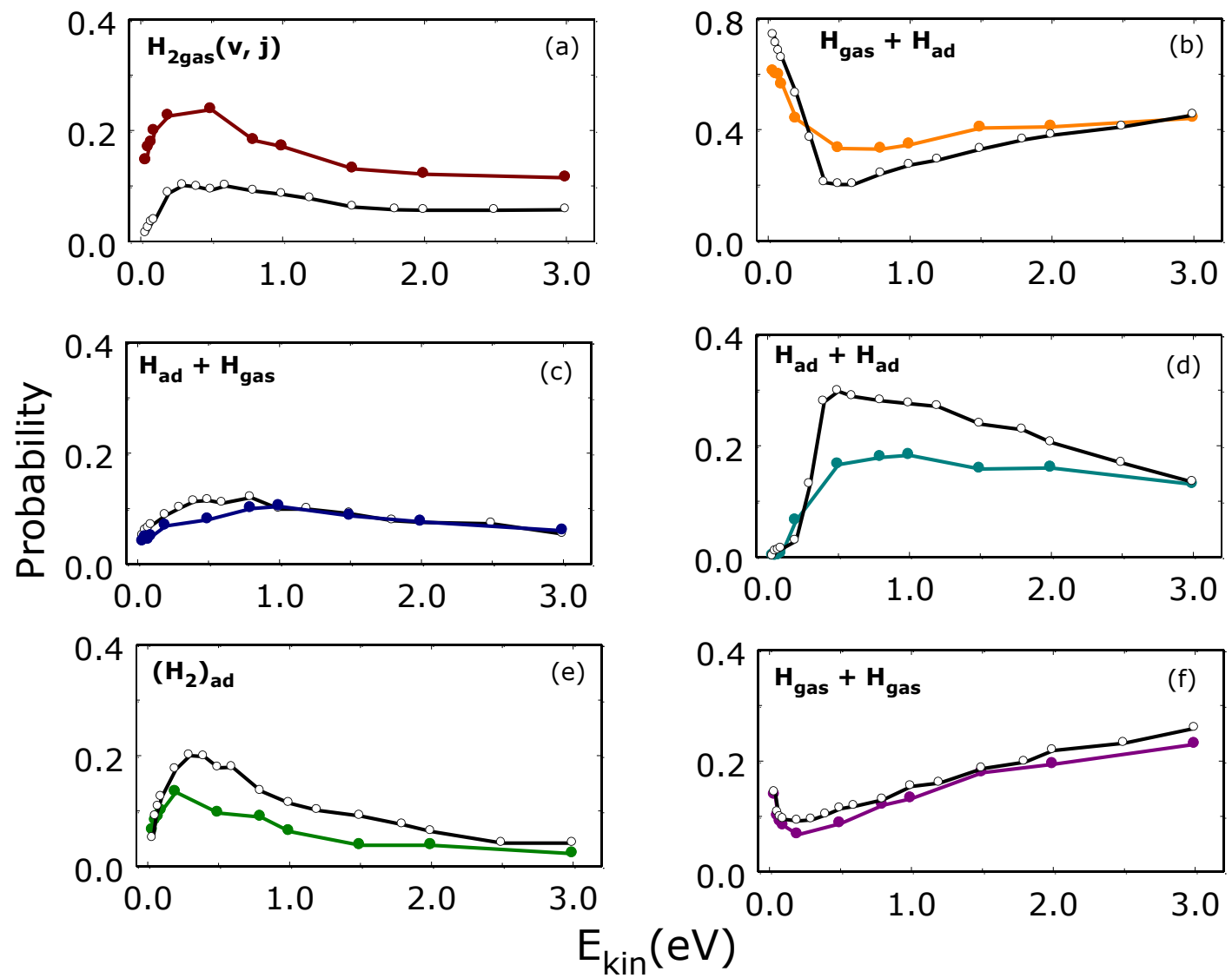

Figure 3 Probabilities for the complete set of processes observed for $\mathrm{H}_{\mathrm{gas}}+\mathrm{H}_{\mathrm{ad}}$ *silica collisions (listed in Eqs. 9(a-f)) at $\mathrm{T}_{\mathrm{S}}=1000 \mathrm{~K}$ and $\theta_{\mathrm{v}}=45^{\circ}$ (color lines and solid symbols). The black lines and open symbols report the probability for the same process but for normal incidence $\left(\theta_{\mathrm{v}}=0^{\circ}\right)$. Note the different Y-scale in panel (b) for the case of $\mathrm{H}_{\text {gas }}$ reflection (Eq. 9b).

The probabilities for $\mathrm{H}_{2 \text {,gas }}$ formation through E-R reaction (Eq. 9a and Figure 3a) present a similar behavior for the two approaching angles. Thus, they rise sharply up to a maximum value for $\mathrm{E}_{\mathrm{kin}} \sim 0.4 \mathrm{eV}$ and then they decrease until reaching a constant value for $\mathrm{E}_{\mathrm{kin}}$ higher than $1.5 \mathrm{eV}$. Nevertheless, the off-normal incidence favours the E-R reaction, whose maximum value of probability is a factor of two greater than that for normal incidence. It is noticeable that the principal process at off-normal incidence corresponds to the reflection of the incoming atom, Eq. (9b and Figure $3 b$ ) for all $E_{\text {kin }}$ values explored at off-normal incidence, whereas in the case of 
normal incidence the adsorption of the second hydrogen atom, Eq. (9d) (Figure 3d) is the main process within the range $E_{\text {kin }}=(0.4-0.8) 0.4-0.8 \mathrm{eV}$. This latter process, instead, has a probability significantly lower in the case of off-normal incidence, mainly in the energy range (0.4-1.5) 0.4 $1.5 \mathrm{eV}$. Finally, no significant differences are observed; with regard to the effect of the impact angle of incoming $\mathrm{H}_{\text {gas; }}$ on the probability of the other surface processes shown in Figures $3 \mathrm{c}$ and 3f, i.e., adsorption + desorption and desorption, respectively.

The effect of the incident angle is stronger when considering the energy partitioning in the E-R recombination process. In particular, Figure 4 reports the average energy fractions distributed into the final states of the new formed $\mathrm{H}_{2 \text {,gas }}$ molecules for the case of off-normal and normal incidence. Although all the degrees of freedom of the new formed $\mathrm{H}_{2 \text {,gas }}$ molecules are involved in the dynamics, in the case of off-normal incidence (Figure $4 \mathrm{a}$ ) and $\mathrm{E}_{\mathrm{kin}}<0.5 \mathrm{eV}$ there is a clear close correlation between the vibrational and translational motions since a gain/loss of vibrational energy corresponds to an almost identical loss/gain of translational energy. The average energy transferred to the surface $\left(\Delta \mathrm{E}_{\mathrm{ph}}\right)$ is very low for both incidence angles and even for the higher $\mathrm{E}_{\mathrm{kin}}$ explored it remains below the $4 \%$ and $8 \%$ for off-normal and normal incidence, respectively. 


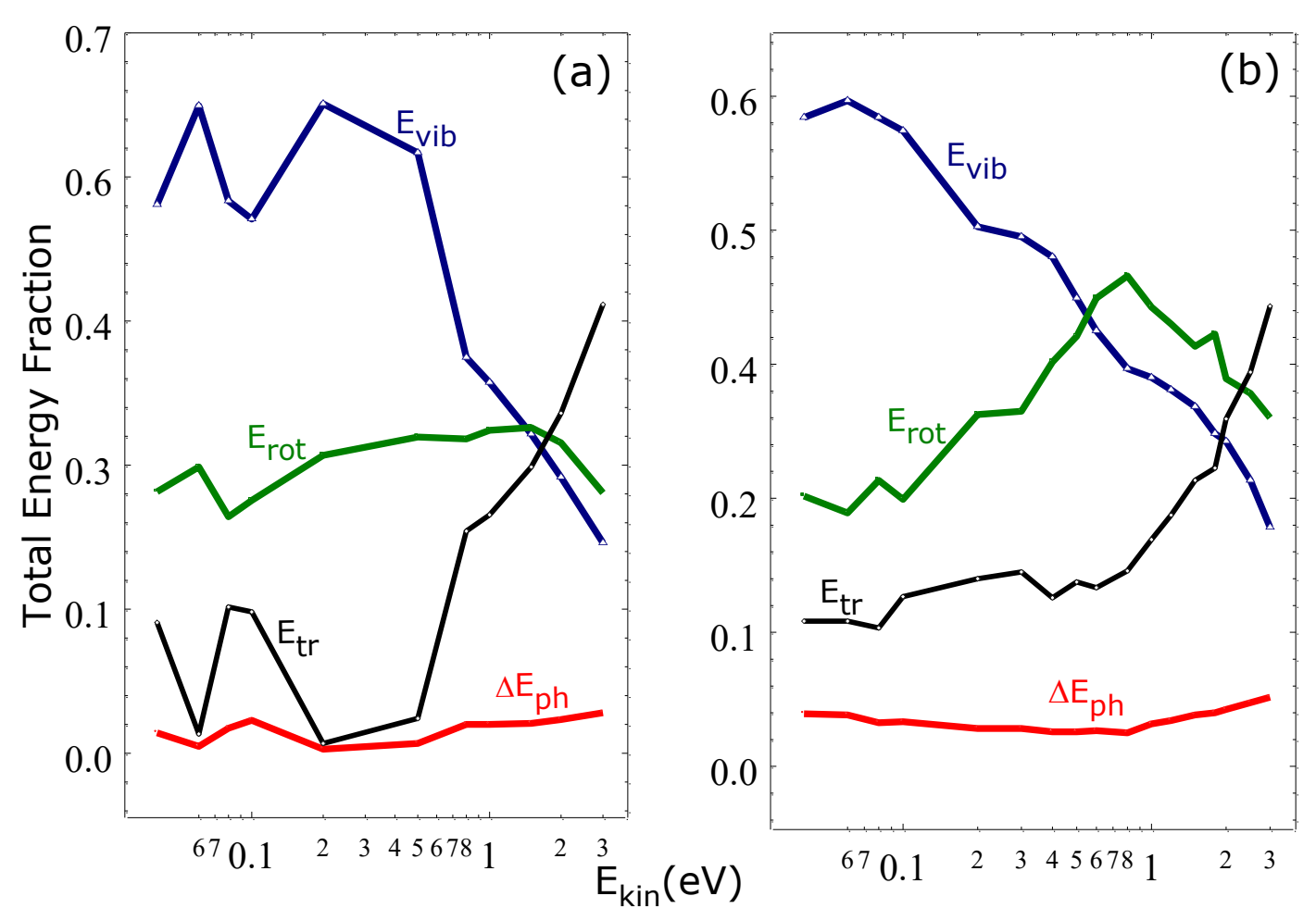

Figure 4 Average total energy fractions transferred to the vibrational $\left(\mathrm{E}_{\mathrm{vib}}\right)$, rotational $\left(\mathrm{E}_{\mathrm{rot}}\right)$ and translational $\left(\mathrm{E}_{\mathrm{tr}}\right)$ motion of the new formed $\mathrm{H}_{2 \text {,gas }}$ molecules as a function of $\mathrm{E}_{\mathrm{kin}}$ at $\mathrm{T}_{\mathrm{S}}=1000 \mathrm{~K}$ and for off-normal (a) and normal (b) incidence. $\Delta \mathrm{E}_{\mathrm{ph}}$ corresponds to the average energy fraction transferred to the solid surface.

NOTES ABOUT FIGURE 4: The two Y-scales are different, please unify them.

The different interplay between the rotational and vibrational energy of formed $\mathrm{H}_{2, \text { gas }}(\mathrm{v}, \mathrm{j})$ molecules can be inferred comparing the roto-vibrational distributions for $\mathrm{E}_{\mathrm{kin}}=0.06 \mathrm{eV}$ for offnormal and normal incidence (Figures 5a and 5b, respectively). The vibrational distributions are peaked at $\mathrm{v}=5$ and 6 for off-normal and normal incidence, respectively. The small difference obtained in vibrational excitation, for the two impinging geometries, can be ascribed to the higher rotational excitation obtained in the case of off-normal incidence at this $\mathrm{E}_{\text {kin. }}$ In fact, in the case of off-normal incidence the average rotational quantum number is higher than that obtained in the 
case of normal incidence: $\langle\mathrm{j}\rangle=12$ and $\langle\mathrm{j}\rangle=10$ respectively. For off-normal incidence the corresponding roto-vibrational distributions appear broader and more densely populated in the medium-high levels.

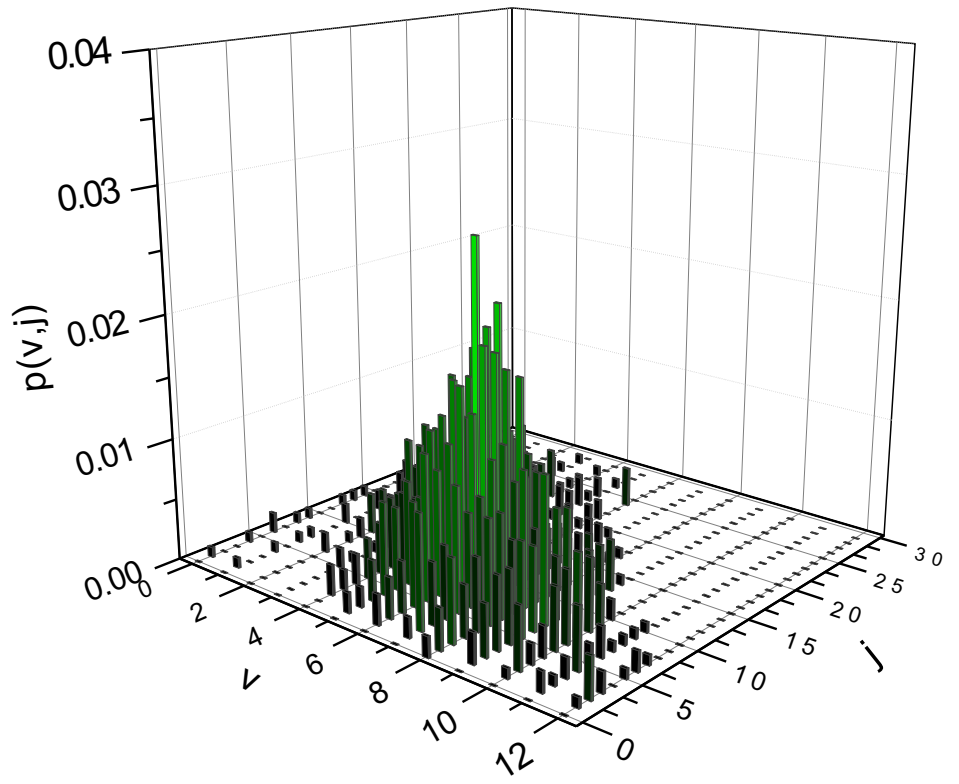

(a)

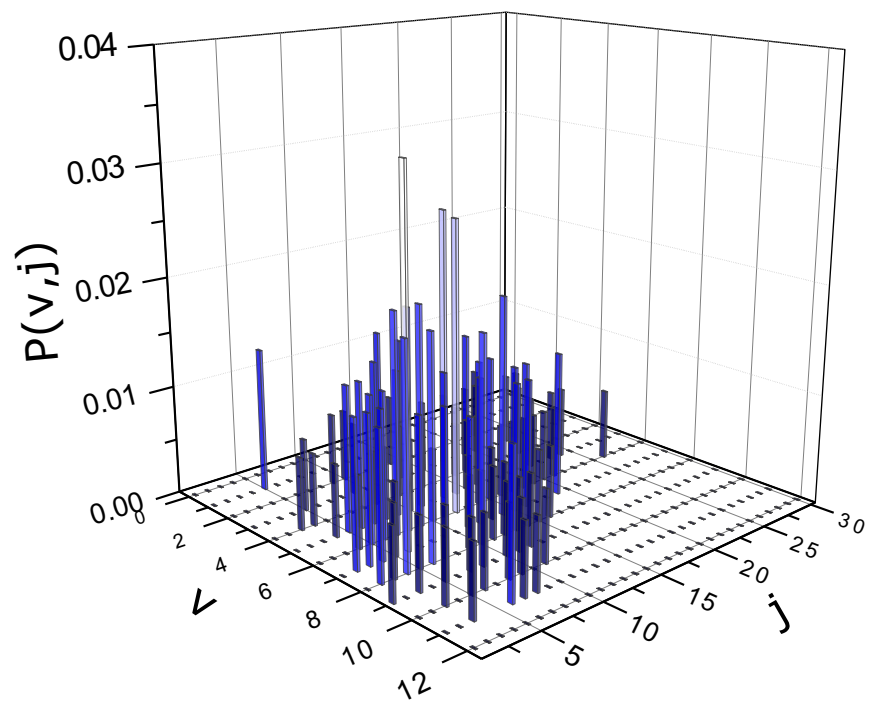

(b)

Figure 5 Roto-vibrational distributions $\mathrm{P}(\mathrm{v}, \mathrm{j})$ of the new formed $\mathrm{H}_{2, \text { gas }}$ molecules by $\mathrm{E}-\mathrm{R}$ reaction (Eq. (9a)) for initial $E_{k i n}=0.06 \mathrm{eV}$ at $\mathrm{T}_{\mathrm{S}}=1000 \mathrm{~K}$ and for off-normal (a) and normal incidence (b). The distributions are normalized to the unit. 
NOTES ABOUT FIGURE 5: The scales in both figures are still different, please unify them. For example, in fig. a, probability is written with small $\mathrm{p}$ and in fig. $\mathrm{b}$, with capital $\mathrm{P}$. The font size in labels also is different. I have still some doubts about Fig. 5b, I am sending you a file (Fig.5capute.jpg) for showing you what I am really seeing, since maybe there is some changes in the figure from your computer. In the case of this figure $5 \mathrm{~b} \mathrm{I}$ am sending you is the same that the one proposed by you, I think that it is better to avoid the use of Fig. $5 \mathrm{~b}$ or maybe use the $2 \mathrm{D}$ plots that you sent us.

The $\mathrm{H}_{2 \text {,gas }}$ vibrational distributions, $\mathrm{P}\left(\mathrm{v}, \mathrm{E}_{\mathrm{kin}}\right)$ are reported in Figures $6 \mathrm{a}$ and $6 \mathrm{~b}$ for off-normal and normal incidence, respectively. It appears that, for both incidence angles considered in the calculations, and for low $\mathrm{E}_{\mathrm{kin}}$, the vibrational distributions are peaked at medium vibrational levels. while at high $\mathrm{E}_{\text {kin }}$ the distributions are broader with maximum shifted towards lower $\mathrm{v}$ values. When collision energy is increased the distribution becomes wider and the peak moves towards lower vibrational levels as can be seen by considering the average vibrational quantum number $<\mathrm{v}>$. $<\mathrm{v}>$ has a step-like trend, being $<\mathrm{v}>=6$ for $0.04<\mathrm{E}_{\mathrm{kin}}<0.1,<\mathrm{v}>=5$ for $0.2<\mathrm{E}_{\mathrm{kin}}<2.5$ and $<\mathrm{v}>=4$ for $E_{k i n}=3.0$. Looking to the vibrational distributions, we it can also be inferred that recombination reaction of hydrogen atoms on silica surface gives rise te produces $\mathrm{H}_{2}$ molecules with non-thermal distributions.
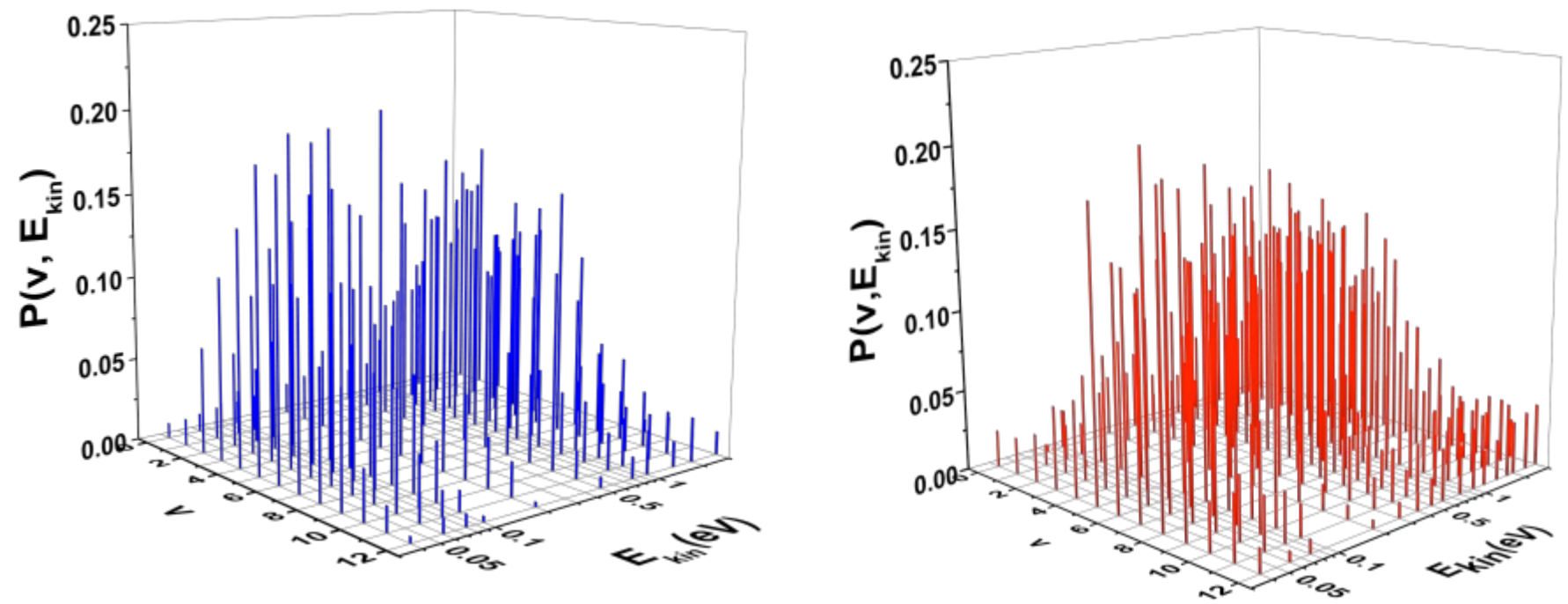
Figure 6 Vibrational distributions $\mathrm{P}\left(\mathrm{v}, \mathrm{E}_{\mathrm{kin}}\right)$ at $\mathrm{T}_{\mathrm{S}}=1000 \mathrm{~K}$ and a) off-normal and $\mathrm{b}$ ) normal incidence.

NOTES ABOUT FIGURE 6: This figure is quite nice but only a few comments about it. First, (a) and (b) labels are missed. Second, the (b) panel should be rotated a bit in order to unify with (a). I suggest using a different set of colors for each set of $E_{k i n}$. Now it is impossible to visualize the different trends for each $\mathrm{E}_{\mathrm{kin}}$ value.

These non-thermal distributions are in agreement with the non-early energy barrier character of E-R channel (Figure 2b) the result of the PES for E-R channel that has a non-early energy barrier (Figure 2b) that enables the activation/de-activation of the formed molecules. In addition, the highest populated vibrational level $v=12$ corresponds to an internal energy of $E(v=12, j=0)=\sim$ $2.44 \mathrm{eV}$ that is in complete agreement with the exothermicity of E-R reaction (2) in the PES (i.e., $\left.\Delta \mathrm{E}_{\mathrm{E}-\mathrm{R}}=-2.4 \mathrm{eV}\right)$.

The non-thermal roto-vibrational distributions obtained in our study are in agreement with results reported in Ref. [43] where high rotational levels up to $\mathrm{j}=17$ are observed for the vibrational state $\mathrm{v}=2$ and confirm the fact that the atom recombination is the main source of roto-vibrational excited molecules for hydrogen plasmas. Obviously, the roto-vibrational energy content of formed $\mathrm{H}_{2, \text { gas }}(\mathrm{v}, \mathrm{j})$ molecules is strictly related to the specific reaction exothermicity, besides the vibrational distributions detected in plasmas might not necessarily be the nascent distributions, as determined in the calculations, but also the results of multiple gas-phase and gas-surface collisions at the plasma-surface boundary layer. Production of high vibrationally high excited $\mathrm{H}_{2}$ molecules has been also observed in experiments at over metal surfaces (e.g., $\mathrm{Cu}$ and W) $[5,8,44]$ and confirmed by dynamical in calculations $[45,46]$.

From the analysis of the trajectories it is also possible to ascertain the mechanism followed by E-R recombination as a function of the incoming collision energy range. The mechanism for both eollision energies is determined by the adsorbed atom. Thus, at low collision energy (i.e., 0.06 
$\mathrm{eV}$ ), when the incoming atom approaches the surface, $\mathrm{H}_{\mathrm{ad}}$ is already out of the minimum potential well geometry so that the molecule is formed far from the surface. At higher kinetic energies (i.e., $0.6 \mathrm{eV}$ ) when the incoming atom reaches the surface, $\mathrm{H}_{\mathrm{ad}}$ is still trapped on the surface by the minimum potential well so that the recombination process takes place closer to the surface. This behavior can be inferred from Figure 7 where the $z$ coordinate for the two hydrogen atoms along with the interatomic distance $r$ as a function of collision time for two typical trajectories at $\mathrm{E}_{\text {kin }}=$ $0.06 \mathrm{eV}$ and $0.6 \mathrm{eV}$ are reported as an example of a the general trends observed examining the complete set of reactive trajectories.

The reaction mechanism followed in the case of off-normal incidence is similar to that observed in the case of normal incidence. 

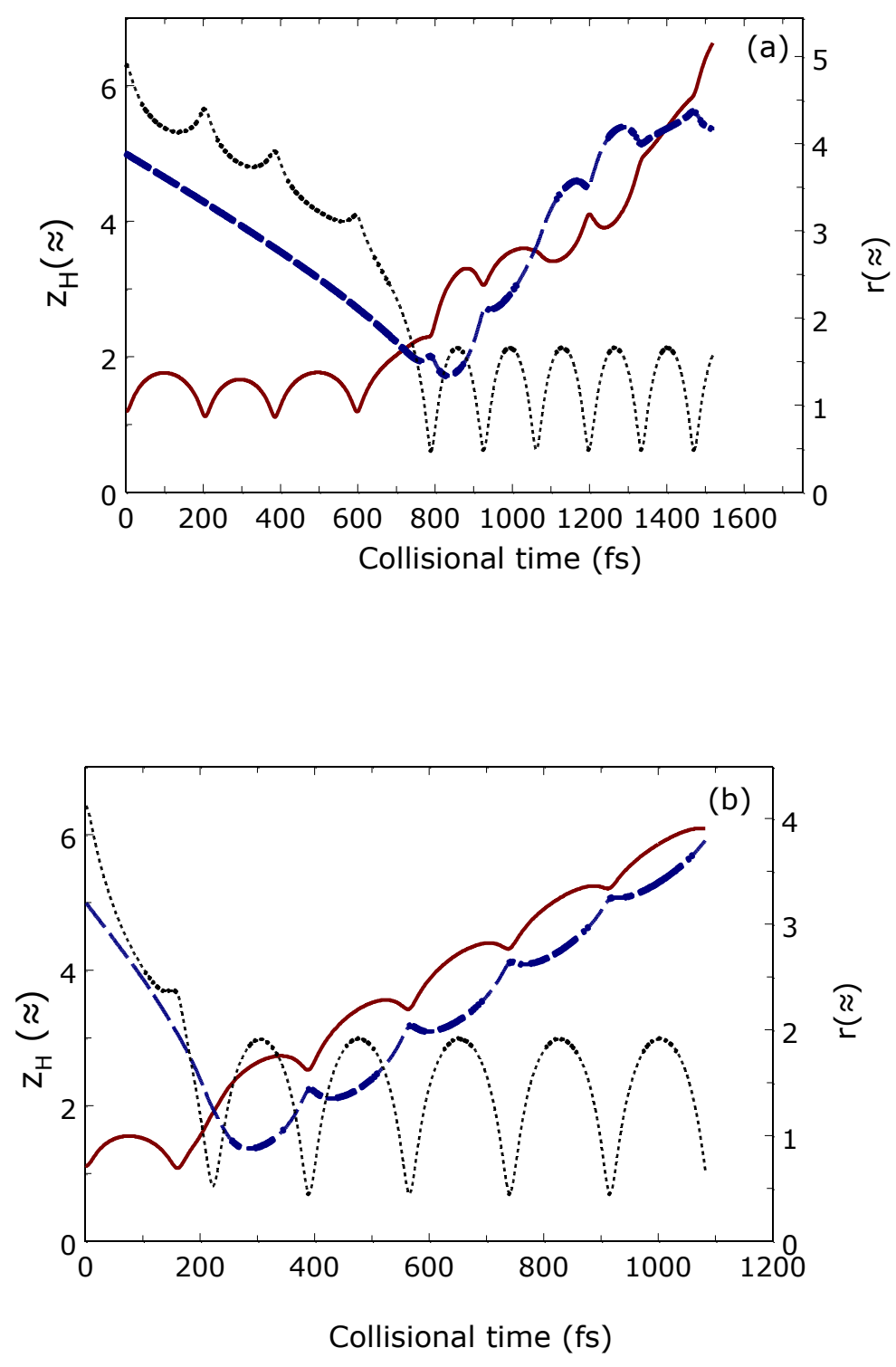

Figure $7 z$ coordinate of adsorbed $\mathrm{H}$ atom (red solid line) and $\mathrm{H}_{\text {gas }}$ atom (blue dashed line) (lefthand axis) and $r$ (black pointed line, right-hand axis) as a function of collision time for a two typical E- $\mathrm{R}$ reactive trajectories for (a) $\mathrm{E}_{\mathrm{kin}}=0.06 \mathrm{eV}$, producing $\mathrm{H}_{2, \mathrm{gas}}\left(\mathrm{v}=6, \mathrm{j}=7\right.$ ) (a) and (b) $\mathrm{E}_{\text {kin }}=$ $0.6 \mathrm{eV}$, producing $\mathrm{H}_{2, \text { gas }}(\mathrm{v}=9, \mathrm{j}=0)(\mathrm{b})$ at $\mathrm{T}_{\mathrm{S}}=1000 \mathrm{~K}$ and normal incidence. 
NOTES ABOUT FIGURE 7: Both panels should be centered. Moreover, the units in axis labels must be modified. I am again sending you a file (Fig.7-capute.jpg) for showing you what I am really seeing, since maybe there is some changes in the figure from your computer.

The surface temperature effect has been also investigated only in the case of normal incidence.

Figure 8 shows that at $\mathrm{T}_{\mathrm{S}}=300 \mathrm{~K}$ the probabilities for E-R reaction (Eq. (8a)), inelastic scattering of $\mathrm{H}_{\mathrm{gas}}$ (Eq. (8b)) as well as for the atomic adsorption+desorption process (Eq. (8c)) increase slightly respect to the values at $\mathrm{T}_{\mathrm{S}}=1000 \mathrm{~K}$ in the complete range of collisional energies explored. This increase is concomitant with a decrease of the probabilities for the atomic hydrogen and molecular hydrogen adsorption processes (Eq. (8d) and Eq. (8e), respectively).
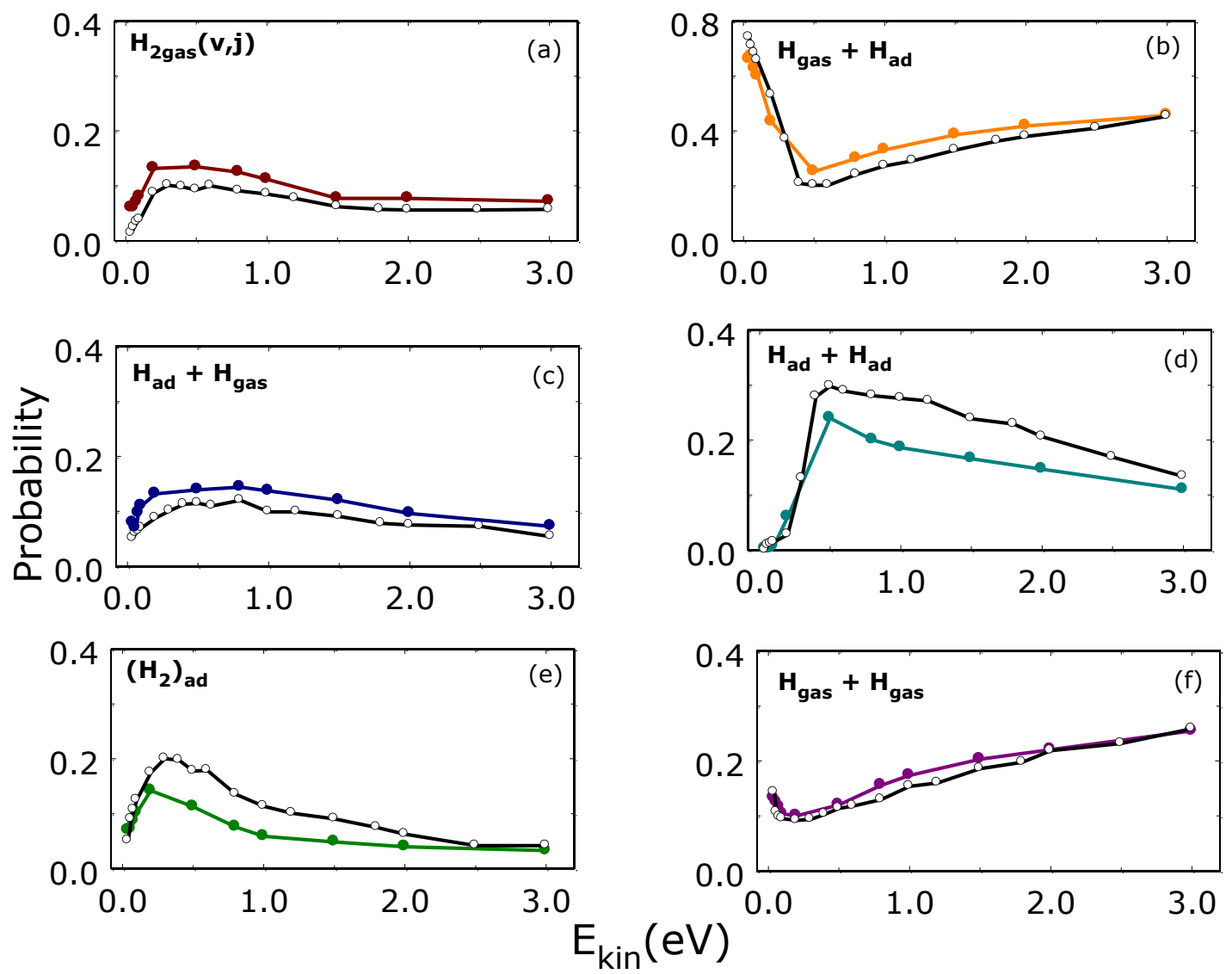

Figure 8 Probabilities for the complete set of processes observed for $\mathrm{H}_{\mathrm{gas}}+\mathrm{H}_{\mathrm{ad}}{ }^{*}$ silica collisions (listed in Eqs. (8a-f)) for normal incidence and $\mathrm{T}_{\mathrm{S}}=300 \mathrm{~K}$ (color lines and solid symbols). For comparison the probability for the same process and normal incidence but for $\mathrm{T}_{\mathrm{S}}=1000 \mathrm{~K}$ are also 
reported (black lines and open symbols). Note the different $\mathrm{Y}$-scale in panel (b) for the case of $\mathrm{H}_{\mathrm{gas}}$ reflection (Eq. (8b)).

NOTES ABOUT FIGURE 8: Panels (b) and (d) are not well aligned with panel (f).

The surface temperature effect is difficult to predict due to the different factors that may contribute to it, but from an accurate analysis of the trajectories it can be pointed out that the different surface temperature effects observed on the processes described in Eq. (8a, b, d, e) can be ascribed to the greater mobility of $\mathrm{H}_{\mathrm{ad}}$ on the surface at $\mathrm{T}_{\mathrm{S}}=1000 \mathrm{~K}$. In fact, in the case of $\mathrm{T}_{\mathrm{S}}=$ $1000 \mathrm{~K}$ the preadsorbed atom moves over the surface changing the interaction site and obviously the final reaction channel. However, it should be noted that the observed surface temperature effect is due only to phonon dynamics. It is also interesting to point out that the same surface temperature effect on the recombination probability was found for $\mathrm{H}$ recombination on graphite (0001) surface [41].

From the analysis of trajectories it emerges that the E-R recombination reaction at $\mathrm{T}_{\mathrm{S}}=300 \mathrm{~K}$ follows a mechanism similar to that found at $\mathrm{T}_{\mathrm{S}}=1000 \mathrm{~K}$ and already described. Regarding the average energy partitioning among the degrees of freedom of the formed $\mathrm{H}_{2, \text { gas }}$ molecules at $\mathrm{T}_{\mathrm{S}}=$ $300 \mathrm{~K}$, a coupling between vibrational and rotational energy fractions is observed mainly for $\mathrm{E}_{\mathrm{kin}}$ lower than $0.5 \mathrm{eV}$. Moreover, the average energy exchanged with the solid surface at $\mathrm{T}_{\mathrm{S}}=300 \mathrm{~K}$ is lower than the value obtained at $\mathrm{T}_{\mathrm{S}}=1000 \mathrm{~K}$, as shown in Figure 9. Once again, this effect is strictly related to the greater mobility of the preadsorbed atom as the surface temperature is increased. 


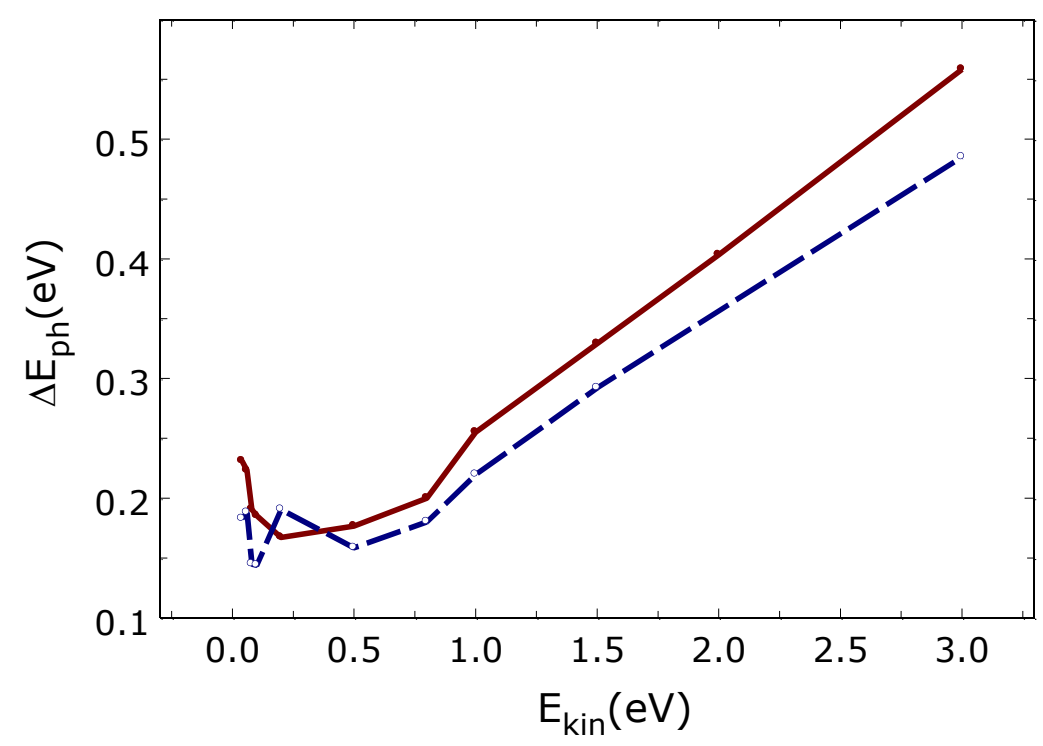

Figure 9 Average values for the energy transferred to the surface in the E-R recombination reaction as a function of the kinetic energy for normal incidence $\left(\theta_{\mathrm{v}}=0^{\circ}\right), \mathrm{T}_{\mathrm{S}}=1000 \mathrm{~K}$ (red solid red line and symbols) and $300 \mathrm{~K}$ (blue dashed blue line and open symbols).

An example of this occurrence is shown in Figure 10 where it is reported the gas-solid interaction potential of the same reactive trajectory at two different surface temperatures as a function of the collision time. $\mathrm{H}_{2 \text {,gas }}$ molecule is formed at $\mathrm{t}=22.0 \mathrm{fs}$ and $\mathrm{t}=22.3 \mathrm{fs}$ at $\mathrm{T}_{\mathrm{S}}=300 \mathrm{~K}$ and $T_{S}=1000 \mathrm{~K}$, respectively. It is worth noting that the interaction potential experienced by the $\mathrm{H}$ atoms in the trajectory, before the reaction, is different and in particular at that time when the gas phase molecule is formed the interaction potential on the hottest surface (red line and solid symbols in Fig. 10) is higher. The different interaction potential is the result of different paths followed on the cold and hot surface by the preadsorbed $\mathrm{H}_{\mathrm{ad}}$ atom. 


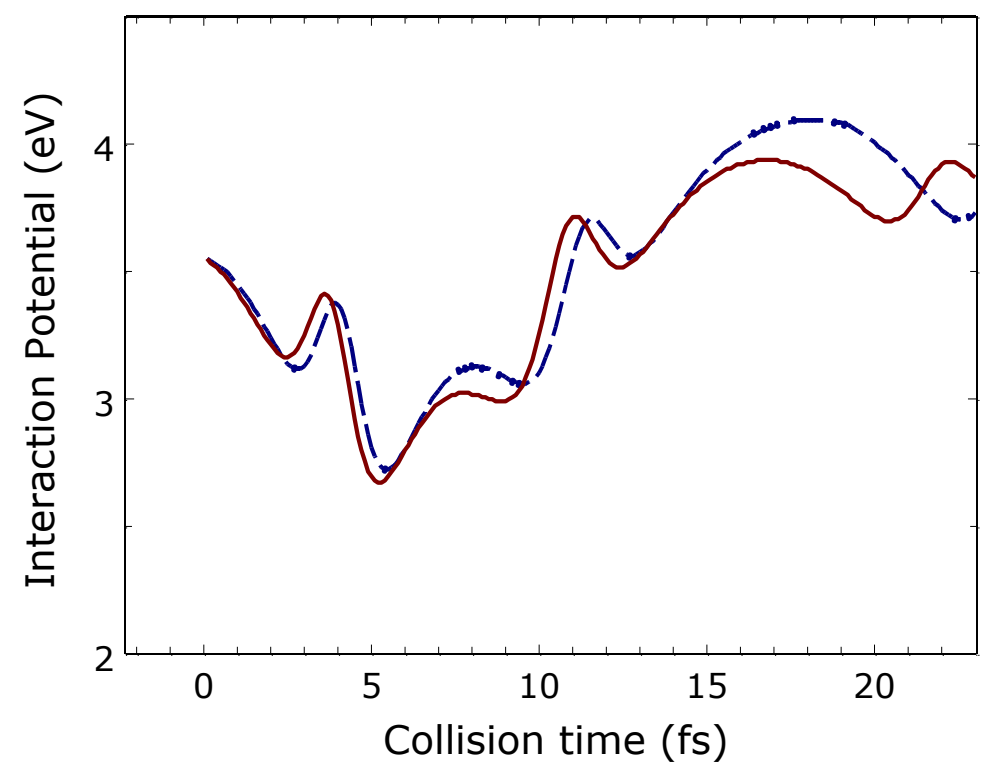

Figure 10 Interaction potential experienced by $\mathrm{H}_{\text {ad }}$ and $\mathrm{H}_{\text {gas }}$ atoms interacting on the surface taken at $T_{S}=300 \mathrm{~K}$ (blue dashed line) and $T_{S}=1000 \mathrm{~K}$ (red solid red line) for a reactive trajectory at $E_{k i n}$ $=0.5 \mathrm{eV}$.

The average vibrational quantum number of the new formed molecules for $\mathrm{T}_{\mathrm{S}}=300 \mathrm{~K}$ is similar to that for $\mathrm{T}_{\mathrm{S}}=1000 \mathrm{~K}$, as a consequence, the determined vibrational distributions have, on the whole, the same behavior for both surface temperatures.

The different surface processes can be subdivided into those that deplete the surface of $\mathrm{H}$ atoms (Eq. 8 a, f) and those that leave the coverage unchanged (Eq. 8 d, e). Processes of Eq. 8 b, c can be substantially neglected leaving unchanged the number of both adsorbed and gas-phase atoms. This analysis in is made in Figure 11 where, for all the simulated conditions, the probability of those processes that deplete and populate the surface the depleting and populating surface processes probabilities are reported together with their difference. 


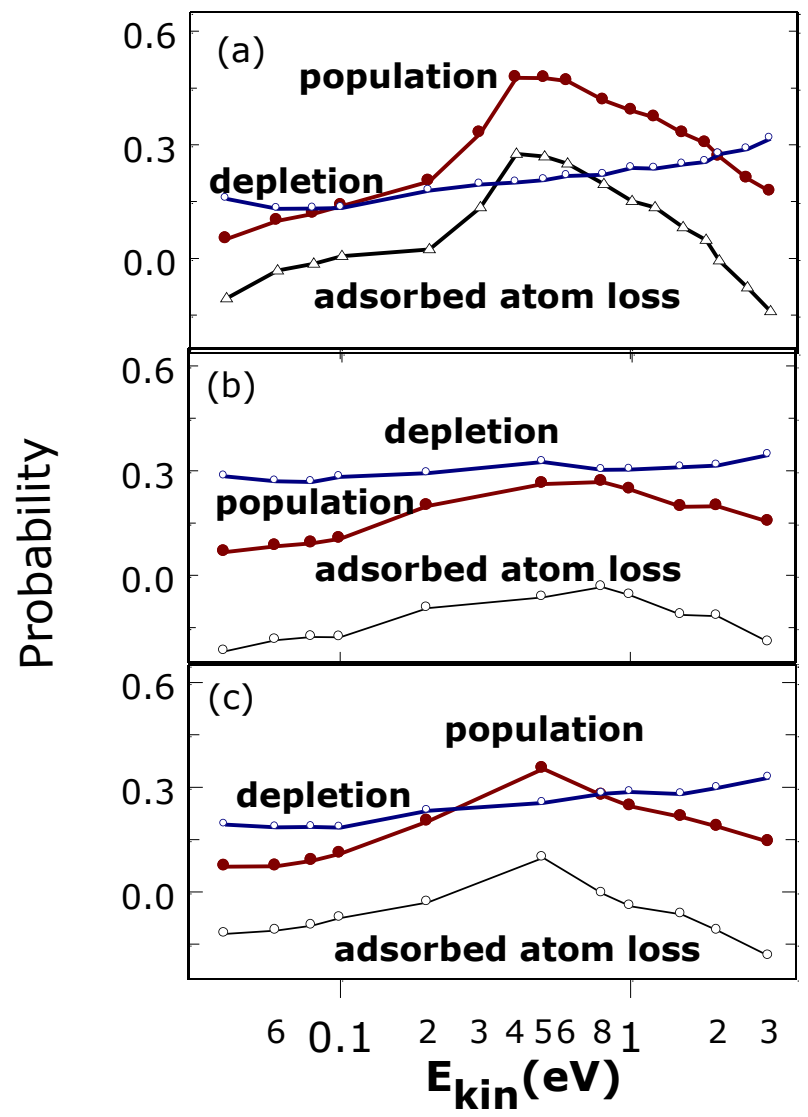

Figure 11 Probability for $\mathrm{H}$ atom depletion and population on the surface. The difference of two probabilities is also reported. (a) normal incidence $\left(\theta_{\mathrm{v}}=0^{\circ}\right), \mathrm{T}_{\mathrm{S}}=1000 \mathrm{~K}$; (b) off-normal incidence $\left(\theta_{\mathrm{v}}=45^{\circ}\right), \mathrm{T}_{\mathrm{S}}=1000 \mathrm{~K}$ and $(\mathrm{c})$ normal incidence $\left(\theta_{\mathrm{v}}=0^{\circ}\right), \mathrm{T}_{\mathrm{S}}=300 \mathrm{~K}$.

NOTES ABOUT FIGURE 11: it would be interesting to use the same color line for each label (depletion in blue, population in red.

Looking to Figure 11 it can be observed shows that for the case of off-normal incidence $\left(\theta_{v}=\right.$ $45^{\circ}$ ) at $\mathrm{T}_{\mathrm{S}}=1000 \mathrm{~K}$ and for that of normal incidence at $\mathrm{T}_{\mathrm{S}}=300 \mathrm{~K}$ (except for $\mathrm{E}_{\text {kin }}=0.5 \mathrm{eV}$ for which we have a little increase in the population probability is observed) there is a high prevalence of depopulation processes. Instead in the case of normal incidence and $\mathrm{T}_{\mathrm{S}}=1000 \mathrm{~K}$, the hydrogen atoms adsorbed on the surface increase for kinetic energy values in the range (0.3-0.6) $0.3-0.6$ 
$\mathrm{eV}$. Outside of this range, a substantially decrement of hydrogen adsorbed atoms is expected. the amount of hydrogen atoms adsorbed diminish significantly.

This circumstance can have an impact on the material technology. In fact, more than the recombination processes, the prevalence of $\mathrm{H}$ atoms adsorption on the silica surface for welldefined collision conditions can change the chemical composition of the gas-phase near the solid substrate and can also be responsible for possible thermal damages of the surface itself because of the large amount of energy transferred to the surface as heat flux.

The global recombination coefficient $\gamma_{\mathrm{E}-\mathrm{R}}$ calculated from Eq. (10), using the probability obtained for normal incidence and for $\mathrm{T}_{\mathrm{S}}=300 \mathrm{~K}$ and $\mathrm{T}_{\mathrm{S}}=1000 \mathrm{~K}$ is reported in Figure 12 as a function of gas temperature ( $\left.T_{\text {gas }}\right)$ within the range $300-3000 \mathrm{~K}$. It is observed that $\gamma_{\mathrm{E}-\mathrm{R}}$ increases as $\mathrm{T}_{\text {gas }}$ does but decreases when $\mathrm{T}_{\mathrm{S}}$ becomes higher. However, if thermal conditions are imposed (i.e., $\mathrm{T}=\mathrm{T}_{\mathrm{S}}=\mathrm{T}_{\mathrm{gas}}$, hereafter $\left.\mathrm{T}\right)$ in $\gamma_{\mathrm{E}-\mathrm{R}}$ calculation, the values obtained are 0.063 and 0.048 at $\mathrm{T}=300$ and $1000 \mathrm{~K}$ (highlighted with an orange box in Figure 12), respectively. This trend is apparently opposite to the experimental behavior observed for silica between $\mathrm{T}=300-900 \mathrm{~K}$ [47], for fused quartz between $194-1250 \mathrm{~K}\left(\gamma=1.1 \times 10^{-3}\right.$ for $\left.\mathrm{T}=1000 \mathrm{~K}\right)$ [14], for Pyrex within the range 275 $-450 \mathrm{~K}\left(\gamma=1.2 \times 10^{-3}\right.$ for $\left.\mathrm{T}=300 \mathrm{~K}\right)[14]$ and for fused silica at $\mathrm{T}=300 \mathrm{~K} \gamma=2.3 \times 10^{-3}$ (near postdischarge) to $\gamma=2.1 \times 10^{-4}$ (late post-discharge) [27]. Moreover, the calculated $\gamma_{\mathrm{E}-\mathrm{R}}$ values are one order of magnitude greater than the experimental $\gamma$ values but an important remark has to be taken into account: the experimental samples of silica did not present any preadsorption of $\mathrm{H}$ atoms. Thus, for an accurate comparison with experiments, it is important noting that the experimental $\gamma$ coefficient is the result of at least a two-step process: atomic adsorption (Eq. (1)) and atomic E-R recombination (Eq. (2)), so the global probability of the recombination process should be given as 
a product of the two corresponding probabilities (i.e., $\mathrm{P}=\mathrm{P}_{\mathrm{ad}} \cdot \mathrm{P}_{\mathrm{E}-\mathrm{R}}$ ). This effect was already discussed in the recombination study of $\mathrm{O} / \mathrm{O}_{2}$ over $\beta$-cristobalite through a microkinetic model [26] leading to a nice comparison with experiments. Since the calculations were done for an Hpreadsorbed surface, we can approximate adsorption probability $\left(\mathrm{P}_{\mathrm{ad}}\right)$ can be approximated as the probability value obtained from Eq. (9d) (i.e., the probability that the incoming atom gets adsorbed when there is another one already adsorbed). Obviously, the correct value of $\mathrm{P}_{\mathrm{ad}}$ should be an average value obtained for the adsorption over a clean surface and also over a surface with several preadsorbed $\mathrm{H}$ atoms. Anyway, the value considered here should be enough as a first approximation, taking into account that in the experiments no data about coverage were are reported. Thus, the global recombination coefficient can be recalculated by replacing in Eq. (10) $\mathrm{P}_{\mathrm{E}-\mathrm{R}}\left(\mathrm{E}_{\text {kin }}, \mathrm{T}_{\mathrm{S}}\right)$ by $\mathrm{P}\left(\mathrm{E}_{\text {kin }}, \mathrm{T}_{\mathrm{S}}\right)=\mathrm{P}_{\mathrm{E}-\mathrm{R}}\left(\mathrm{E}_{\mathrm{kin}}, \mathrm{T}_{\mathrm{S}}\right) \cdot \mathrm{P}_{\mathrm{ad}}\left(\mathrm{E}_{\text {kin }}, \mathrm{T}_{\mathrm{S}}\right)$. By doing this, two approximate values of $\gamma=3.720 \times 10^{-3}$ and $5.185 \times 10^{-3}$ for $\mathrm{T}=300$ and $1000 \mathrm{~K}$, respectively are obtained. These two values reproduce better the T-dependence and also the order of magnitude of the experimental $\gamma$ values $[14,27,47]$.

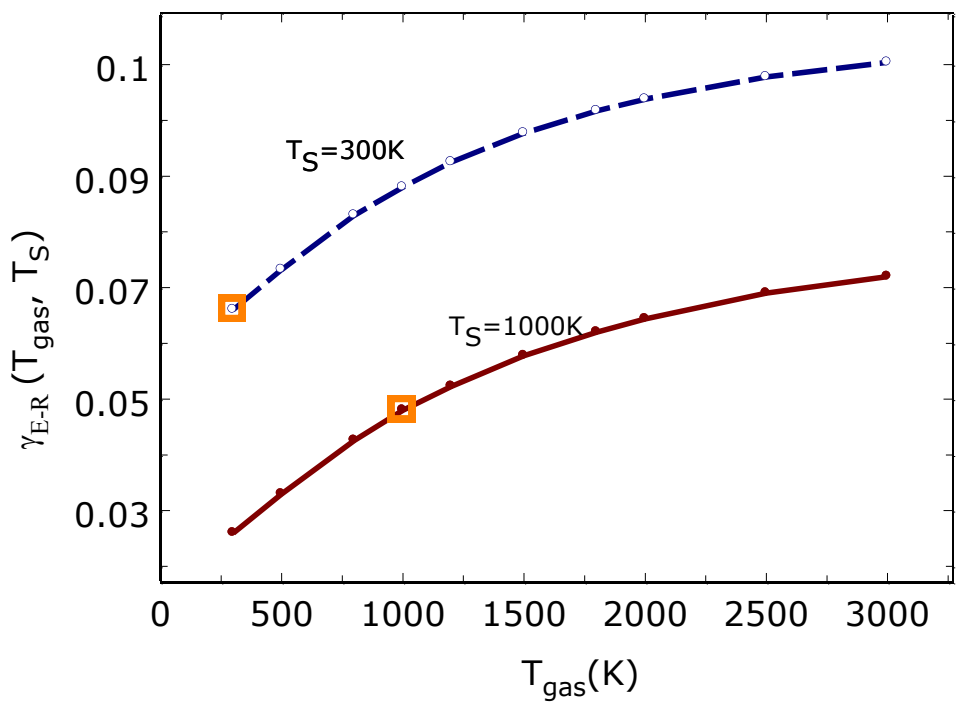


Figure 12 Global atomic E-R recombination coefficient at several gas temperatures $\left(\mathrm{T}_{\mathrm{gas}}\right)$ for normal incidence and $\mathrm{T}_{\mathrm{S}}=300 \mathrm{~K}$ (blue dashed line an open symbols blue) and $1000 \mathrm{~K}$ (red solid line and symbols red).

The slight differences between the results reported here and the experimental ones [14, 27, 47] could be ascribed to the fact that in the present study the adsorbed atom is placed in a well-defined site on the surface, while in the experiment the atom can be adsorbed also in other surface sites, so that the measured recombination coefficient is an average value over all active sites on the surface. Another point concerns the silica structure used. Thus, in the present work a silica $\beta$-cristobalite surface is used while in Refs. [14, 27, 47] quartz, Pyrex or fused silica surfaces were studied. Indeed, different silica polymorphs exhibit a different behavior in the same conditions, both for recombination and for adsorption processes [14, 48, 49]. Furthermore, well-defined values of both gas and surface temperatures together with fixed impinging angles were assumed in the present study while in the experimental setup they were not.

Table 1: Recombination coefficients $\gamma(v)$ for $T_{S}=T_{\text {gas }}=1000 \mathrm{~K}$

\begin{tabular}{|c|c|}
\hline $\mathbf{v}$ & $\gamma(\mathbf{v})$ \\
\hline 0 & 0.021 \\
\hline 1 & 0.025 \\
\hline 2 & 0.047 \\
\hline 3 & 0.086 \\
\hline 4 & 0.109 \\
\hline 5 & 0.167 \\
\hline 6 & 0.168 \\
\hline 7 & 0.134 \\
\hline 8 & 0.111 \\
\hline
\end{tabular}




\begin{tabular}{|c|c|}
\hline 9 & 0.067 \\
\hline 10 & 0.032 \\
\hline 11 & 0.024 \\
\hline 12 & 0.006 \\
\hline
\end{tabular}

As aforementioned, the recombination coefficients are very useful in kinetic modeling and CFD calculations for hydrogen plasmas kinetics and even more the state-to-state recombination coefficients $\gamma(\mathrm{v})$ reported inTable 1 for $\mathrm{T}_{\mathrm{S}}=1000 \mathrm{~K}$, with the greatest values within the range $5<\mathrm{v}<7$.

\section{Concluding Remarks}

The recombination of hydrogen atoms on a $\beta$-cristobalite surface via an E-R mechanism was studied together with the other competitive elementary processes. In order to determine the influence of the incident angle of the atomic flux hitting the surface on the dynamics, two sets of initial conditions have been assumed: normal $\left(\theta_{\mathrm{v}}=0^{\circ}\right)$ and off-normal $\left(\theta_{\mathrm{v}}=45^{\circ}\right)$ incidence. At high surface temperature $\left(T_{S}=1000 \mathrm{~K}\right)$ the main process at all collision energies $\left(E_{k i n}\right)$ explored for off-normal and normal incidence corresponds to the reflection of the incoming atom. Regarding the adsorption of the second hydrogen atom (as separated atoms or as a new formed and adsorbed molecule), it becomes the main process for $\theta_{\mathrm{v}}=0^{\circ}$ at $\mathrm{E}_{\mathrm{kin}} \sim 0.5 \mathrm{eV}$. E-R reaction is favoured for off-normal incidence whereas the other processes benefit from normal incidence. The shape of the E-R probabilities are similar for the two incidence angles showing a maximum value at $\mathrm{E}_{\text {kin }}=0.4$ $\mathrm{eV}$, which is a factor of two greater in the case of off-normal incidence. 
The atomic recombination dynamics has been investigated in detail. Thus, for the $\mathrm{H}_{2, \text { gas }}$ formed molecules the energetics, as well as their roto-vibrational distributions have been determined, showing a different coupling between the degrees of freedom for the two different incident conditions. Particularly, these molecules are formed in the medium-high lying vibrational levels and rotationally excited. The energy transferred to the surface is very small, below the $4 \%$ and $8 \%$ for off-normal and normal incidence, respectively. The E-R mechanism is similar in the case of both incidences and it corresponds to a direct mechanism.

The $T_{S}$ effect was also investigated at normal incidence. At $T_{S}=300 \mathrm{~K}$, the probability of $E-R$ reaction and the inelastic scattering of $\mathrm{H}_{\text {gas }}$ increase slightly in the complete range of $\mathrm{E}_{\mathrm{kin}}$ considered. In addition, a decrease of the probabilities for the atomic hydrogen and molecular hydrogen adsorption processes is also observed. The different $T_{S}$ effect on the processes are is attributed to the greater mobility of $\mathrm{H}_{\mathrm{ad}}$ on the surface at $\mathrm{T}_{\mathrm{S}}=1000 \mathrm{~K}$. For E- $\mathrm{R}$ recombination, the mechanism is similar at the two temperatures. The $\mathrm{T}_{\mathrm{S}}$ effect observed is the same reported for $\mathrm{H}$ recombination on graphite (0001) [41]. At $\mathrm{T}_{\mathrm{S}}=300 \mathrm{~K}$ the energy exchanged with the surface is also lower than that at $T_{S}=1000 \mathrm{~K}$, while the average vibrational quantum number of the new formed molecules is similar for both $\mathrm{T}_{\mathrm{s}}$.

Two atomic recombination coefficients were calculated $\left(\gamma_{\mathrm{E}-\mathrm{R}}\right.$ and $\left.\gamma\right)$. In the first one only the E$\mathrm{R}$ probability $\left(\mathrm{P}_{\mathrm{E}-\mathrm{R}}\right)$ was taken into account, while in the second one the probability of the preadsorption of hydrogen atom was also considered (i.e., $\mathrm{P}=\mathrm{P}_{\mathrm{ad}} \cdot \mathrm{P}_{\mathrm{E}-\mathrm{R}}$ ), since it is a necessary step to produce the E-R reaction. The more accurate comparison with experiments was obtained when the preadsorption process of $\mathrm{H}$ atoms was well included. The calculated $\gamma$ values reproduce the $\mathrm{T}$ dependence and also the order of magnitude of the experimental values. Nevertheless, slight differences may be attributed to the polycrystalline nature of surfaces used in experiments and also 
to the fact that trajectories were run at precise values of gas and surface temperatures and for selected incidence angles.

The obtained results confirm $\mathrm{H}$ atom recombination at $\beta$-cristobalite surface as a source of roto-vibrationally excited $\mathrm{H}_{2}$ molecules in low-temperature hydrogen plasmas also in the case of silica substrate as previously observed for metal surfaces.

\section{Acknowledgements}

This work was supported by the European Commission research funding (Project FP7-SPACE2009-242311), by the Spanish Ministry of Science and Innovation (Project CTQ2009-07647), by the Autonomous Government of Catalonia (Project 2009SGR1041) and in part by the Italian Ministry of Education, University and Research in the framework of the PRIN N. 2008KJX4SN Project.

\section{References}

${ }^{1}$ M Cacciatore and M Rutigliano, 2009 Plasma Sources Sci. Technol. 18023002

${ }^{2}$ J. Amorim, J. Loureiro, D. Schram, 2001 Chem. Phys. Lett. 346 443-448

${ }^{3}$ M. Péalat, JP. E. Taran, M. Bacal, and F. Hillion, 1985 J. Chem. Phys. 82 4943-4953

${ }^{4}$ R. F. G. Meulenbroeks, D. C. Schram, M. C. M. van de Sanden, and J. A. M. van der Mullen, 1996 Phys. Rev. Lett. 76 1840-1843

${ }^{5}$ R. I. Hall, I. Cădež , M. Landau, F. Pichou and C. Schermann, 1988 Phys. Rev. Lett. 60 337-340

${ }^{6}$ O. Gabriel, J. J. A. van den Dungen, D. C. Schram, and R. Engeln, 2010 J. Chem. Phys. 132 104305 
${ }^{7}$ T. Mosbach, H.-M. Katsch, and H. F. Döbele, 2000 Phys. Rev. Lett. 85 3420-3423

${ }^{8}$ P. J. Eenshuistra, J. H. M. Bonnie, J. Los and H. J. Hopman, 1988 Phys Rev. Lett. 60 341-344

${ }^{9}$ O. Peña, S. Muhl, W. López , L. Rodríguez-Fernández , J.L. Ruvalcaba-Sil, 2010 Thin Solid Films 518 3156-3159

${ }^{10}$ G. Vidali, 2013 J. Low Temp Phys. 170 1-30

${ }^{11}$ D. A. Stewart, Y. K. Chen, B. J. Banford and A. B. Romanowsky, AIAA, 95-2013 (1995)

${ }^{12}$ C.D. Scott, "Catalytic recombination of nitrogen and oxygen on high temperature reusable surface insulation" in Progress in Astronautics and Aeronautics, A. L. Crosbie (Eds), Vol. 77, (1981)

${ }^{13}$ M. Balat-Pichelin, J. M. Badie, R. Berjoan and P. Boubert, 2003 Chem. Phys. 291 181-194

${ }^{14}$ Y. C. Kim and M. Boudart, 1991 Langmuir 7 2999-3005

${ }^{15}$ F. Nasuti, M. Barbato and C. Bruno, 1996 J. Thermophys. Heat Transf. 10 131-136

${ }^{16}$ M. Cacciatore, M. Rutigliano and G.D. Billing, 1999 J. Thermophys. Heat Transf. 13 195-203

${ }^{17}$ L. Bedra, M. Rutigliano, M. Balat-Pichelin and M. Cacciatore, 2006 Langmuir 22 7208-7216

${ }^{18}$ C. Arasa, P. Gamallo and R. Sayós, 2005 J. Phys. Chem. B 109 14954-14964

${ }^{19}$ C. Arasa , V. Morón, H.F. Busnengo and R. Sayós, 2009 Surf. Sci. 603 2742-2751

${ }^{20}$ I. Armenise, M. Capitelli, C. Gorse, M. Cacciatore and M. Rutigliano, 2000 J. Spacecraft Rockets 37 318-323

${ }^{21}$ I. Armenise, M. Rutigliano, M. Cacciatore and M. Capitelli, 2011 J. Thermophysics Heat Transfer 25 627-632

${ }^{22}$ V. L. Kovalev and A. F. Kolesnikov, 2005 Fluid Dyn. 40 669-693

${ }^{23}$ J. Thoemel, E. Cosson and O. Chazot, Proceedings of the Sixth European Symposium on Aerothermodynamics for Space Vehicles, Versailles, France, ESA SP-659, session 17, 1-14 (2008) 
${ }^{24}$ B. Halpern and D. E. Rosner, 1978 J. Chem. Soc. Farad. Trans. 174 1883-1912

${ }^{25}$ T. Kurotaki, AIAA, 2366, 1-7 (2000)

${ }^{26}$ V. Morón, P. Gamallo, L. Martin-Gondre, C. Crespos, P. Larregaray and R. Sayós, 2011 Phys. Chem. Chem. Phys. 13 17494-17504

${ }^{27}$ A. Rousseau, G. Cartry, and X. Duten, 2001 J. Appl. Phys. 89 2074-2078

${ }^{28}$ G. D. Billing, Dynamics of Molecule Surface Interactions, John Wiley\&Sons, New York, (2000)

${ }^{29}$ P. Gamallo, M. Rutigliano, S. Orlandini, M. Cacciatore and R. Sayós, 2012 AIP Conf. Proc., 1501, 1129-1136

${ }^{30}$ G. Kresse and J. Hafner, 1993 Phys. Rev. B 48 13115-118

${ }^{31}$ G. Kresse and J. Hafner, 1994 Phys. Rev. B 49 14251-14269

${ }^{32}$ G. Kresse and J. Furthmüller, 1996 Comput. Mater. Sci. 6 15-50

${ }^{33}$ G.Kresse and J. Furthmüller, 1996 Phys. Rev. B 54 11169-11186

${ }^{34}$ H. J. Monkhorst and J. D. Pack, 1976 Phys. Rev. B, 13, 5188-5192

${ }^{35}$ J. P. Perdew, K. Burke and M. Ernzerhof, 1996 Phys. Rev. Lett. 77 3865-3868

${ }^{36}$ B. P. Feuston and S. H. Garofalini, 1988 J. Chem. Phys. $895818-5824$

${ }^{37}$ P. N. Sen and M. F. Thorpe, 1977 Phys. Rev. B 15 4030-4038

${ }^{38}$ K. P. Huber and G. Herzberg, Molecular Spectra and Molecular Structure: IV. Constants of Diatomic Molecules, Van Nostrand Reinhold Company, New York, (1979)

${ }^{39}$ M. Cacciatore and G. D. Billing, 1990 Surf. Sci. 232 35-50

${ }^{40}$ M. Cacciatore and G. D. Billing, 1996 Pure \& Appl. Chem. 68 1075-1081

${ }^{41}$ M. Rutigliano and M. Cacciatore, 2008 ChemPhysChem 9 171-181

42 J. T. Muckerman, 1971 J. Chem. Phys. 54 1155-1161

${ }^{43}$ P. Vankan, D.C. Schram, R. Engeln, 2004 Chem. Phys. Lett. 400 196-200 
${ }^{44}$ S. Markelj and I. Čadež, 2011 J. Chem. Phys. 134124707

${ }^{45}$ B. Jackson and M. Persson, 1992 J. Chem. Phys. 96 2378-2386

${ }^{46}$ M. Rutigliano and M. Cacciatore, 2011 Phys. Chem. Chem. Phys. 13 7475-7484

${ }^{47}$ M. Green, J.R. Jennings, J. W. Linnett and D. Schofield, 1959 Trans. Farad. Soc. 55 2152-2161

${ }^{48}$ M. Rutigliano, C. Zazza, N. Sanna, A. Pieretti, G. Mancini, V. Barone and M. Cacciatore, 2009

J. Phys. Chem. A 113 15366-15375

${ }^{49}$ C. Zazza, M. Rutigliano, N. Sanna, V. Barone and M. Cacciatore, 2012 J. Phys. Chem. A 116 $1975-1983$ 